\title{
Variation of Coda wave attenuation in two different Tectonic Areas in the Iranian plateau, Alborz and NW Zagros
}

\author{
Reza Emami ${ }^{1}$, Mehdi Rezapour*,1, Ulrich Achauer ${ }^{2}$ \\ (1) Institute of Geophysics, University of Tehran, Tehran, Iran \\ (2) Institut de Physique de Globe de Strasbourg (IPGS), Strasbourg, France
}

Article history: received October 19, 2018; accepted September 16, 2019

\begin{abstract}
The attenuation of coda wave in Alborz and NW Zagros has been estimated using the single backscattering (SBS) and the single isotropic scattering (SIS) methods at 9 frequency bands with central frequencies of 1, 1.5, 2, 3, 4, 6, 8, 12 and $16 \mathrm{~Hz}$. The database consisted of 677 local earthquakes (418 events in the Alborz region and 259 events in the NW Zagros region) with the $\mathrm{M}_{\mathrm{N}}$ magnitude range from 3.0 to 5.7. A total of 8,717 seismograms with signal-to-noise ratios of greater than 3 and epicentral distances less than $200 \mathrm{~km}$ were used. To investigate the depth variation of attenuation in this study, the coda quality factor $Q_{c}$ was estimated in each area at epicentral distance range of $R<100 \mathrm{~km}$ and $100<R<200 \mathrm{~km}$, through 11 coda window lengths between 10 and $60 \mathrm{~s}$. The estimated average frequency-dependent relation of $Q_{c}=Q_{0} f^{n}$ at coda window length of 10 to $60 \mathrm{~s}$ varies from $66 f^{1.04}$ to $164 f^{0.72}$ in Alborz and $66 f^{0.99}$ to $157 f^{0.76}$ in NW Zagros. In this study, the value of the frequency-dependent parameter decreases with increasing the coda window lengths, and suggests that the lithosphere becomes more homogenous with increasing depth.

Furthermore, the coda wave quality factor was determined from all three components.We found that there is no significant difference in obtained results by using the vertical and horizontal components. This indicates that the seismic waves encounter similar heterogeneities and attenuation in the vertical and horizontal directions in the study area.The average frequencydependent relations of coda waves have been derived $Q_{c}=109 f^{0.87}$ and $Q_{c}=108 f^{0.86}$, for the Alborz and NW Zagros regions, respectively, usingthe SBS model at the coda window length of 25s. Comparison of estimated coda- $Q$ values show that, the obtained $Q_{c}$ values using the SIS method are slightly higher than that those obtained using the SBS method.
\end{abstract}

Keywords: Attenuation, Coda waves, SBS and SIS methods, Alborz, NW Zagros.

\section{Introduction}

The seismic attenuation, as an important characteristic in the modern seismology, has an inevitable effect on the determination of the source mechanism, the waveform modeling, the simulation of strong ground motion and the seismic hazard analysis [Jackson and Anderson, 1974; Farrokhi et al., 2016; Soham and Abhishek, 2016]. 


\section{Reza Emami et al.}

The attenuation of seismic waves in the lithosphere is also an important property for studying the regional earth structure and seismotectonic activity [Kumar et al., 2005].

Seismic attenuation as amplitude decay through wave propagation is caused by two distinct physical processes: elastic and anelastic properties of the medium. Attenuation is usually expressed as the inverse of the quality factor $(Q)$ and is generated by two main sources: scattering due to heterogeneities and intrinsic absorption. The existing random heterogeneities throughout the earth's lithosphere are responsible for the generation of late-arriving wave trains in the tail portion of seismograms -after the arrival of major wave types such as $\mathrm{P}, \mathrm{S}$, and surface wavesrecords of the local and regional events, which are called 'coda waves' [Aki, 1969; Aki and Chouet, 1975; Sato, 1977; Parvez et al., 2008; Sato et al., 2012; Obermann et al., 2012; Havskov et al., 2016]. Coda waves are backscattered body waves [Aki, 1969; 1980], which their amplitude decreases due to attenuation (including scattering) and geometrical spreading [Havskov et al., 2016].

Aki and Chouet [1975] and Sato [1977] proposed the single scattering model to calculate the attenuation of seismic waves from the decay of coda waves. The multiple-scattering model which is suggested by Gao et al., [1983] is another model to estimate the attenuation of coda waves [Kumar et al., 2005]. Unlike the earlier part of the coda waves, the effect of secondary and tertiary scattered waves is not negligible for the later part [Kopnichev, 1977], therefore, the multiple-scattering model is mainly for lapse times greater than $100 \mathrm{~s}$ [Gao et al., 1983; Kumar et al., 2005; Sedaghati and Pezeshk, 2016a]. At very long lapse times, the coda- $Q$ is almost entirely influenced by intrinsic absorption [Shapiro et al., 2000; Hovskov et al., 2016]. In other words, at long lapse time, coda waves enter in the diffusive regime, which implies $Q_{c}{ }^{-1}=Q_{i}^{-1}$ in a simple uniform half-space [Shapiro et al., 2000]. It should be pointed out that the estimated coda- $Q$ from the single scattering model represents an effective attenuation including intrinsic absorption and scattering loss [Shapiro et al., 2000; Jin and Aki, 2005]. In recent years, the importance of multiple-scattering model has grown and many studies have been carried out by this model [e.g., Calvet and Margerin, 2013; Calvet et al., 2013; De Siena et al., 2016; Galluzzo et al., 2015; Havskov et al., 2016]. Nonetheless, the single scattering model still remains a well-accepted model to comprehend the tectonic processes at the crustal and lithospheric scale, because it offers an easier way to estimate the attenuation properties of the Earth [Irandoust et al., 2015].

After the advent of the coda wave theory by Aki, [1969], the attenuation of coda waves has been estimated for different regions in the world using single-scattering model [e.g., Singh and Hermann, 1983; Mak et al., 2004; Ma'hood and Hamzehloo, 2009; Rahimi et al., 2010; Sertçelik, 2011; Havskov et al., 2016; Sedaghati and Pezeshk, 2016a]. Aki, [1969] as a pioneer of the single scattering method, used the local earthquakes with a magnitude range of 2.5-5.0 to analyze the seismic coda in the Parkfield region. By applying this method, numerous researchers [e.g., Aki, 1969; Kumar et al., 2005; Kim et al., 2006; Chung et al., 2009; Rahimi et al., 2010; Sharma et al., 2015; Ma'hood, 2014; Farrokhi et al., 2015; Sedaghati and Pezeshk, 2016a; Dobrynina et al., 2017] have estimated the $Q_{c}$ values using the local earthquakes with different magnitude ranges of 0.6-6.1. The successful application of the single scattering method for estimating $Q_{c}$ value in active/stable regions using local earthquakes with $M<6.0$, has been proven [Irandoust et al., 2015].

As mentioned earlier, the inverse of the quality factor $(Q)$, which indicates the wave transmission quality of the bedrock, represents the attenuation properties of the medium [Chandler et al., 2006]. Generally, the quality factor depends on the frequency of the seismic waves, therefore, it is expressed by the power-law equation as follows: $Q=Q_{0} f^{n}$, where $f$ is frequency, $Q_{0}$ and $n$ are constants that represent the quality factor at $1 \mathrm{~Hz}$ and frequencydependent parameter, respectively. These constants vary from region to region according to the attenuation characteristics of the seismic waves [Aki and Chouet, 1975; Singh and Hermman, 1983]. Previous studies of the seismic quality factor in different regions in the world have shown that low $Q_{0}$ values $\left(Q_{0}<200\right)$ with higher $n$ values $(n>0.7)$ are indicators of tectonically active regions [Aki and Chouet, 1975; Roecker et al., 1982; Sato and Fehler, 1988; Mak et al., 2004; De Lorenzo et al., 2013; Ma'hood, 2014; Sedaghati and Pezeshk, 2016a]. High values of $Q_{0}$ $\left(Q_{0}>600\right)$ with low $n(n<0.4)$ represent tectonically inactive and stable regions [Singh and Herrmann, 1983; Pulli, 1984; Pujades et al., 1991; Sedaghati and Pezeshk, 2016a]. Moreover, some studies reported intermediate values for $\mathrm{Q}_{0}$ and $n\left(200<\mathrm{Q}_{0}<60,0.4<n<0.7\right)$ in tectonically moderate regions [Scherbaum and Kisslinger, 1985; Kumar et al., 2005, Sedaghati and Pezeshk, 2016a].

Various studies have been carried out to investigate the seismic wave attenuation in the Alborz and Zagros regions using different datasets and methods [e.g., Motazedian, 2006; Rahimi et al., 2010; Motaghi and Ghods, 2012; Naghavi et al., 2012, Farrokhi et al., 2015]. In this study, first, the attenuation of coda waves is estimated in the 
Variation of coda wave attenuation in the Alborz and NW Zagros regions

\begin{tabular}{|c|c|c|c|c|}
\hline Region & Sub region & $\begin{array}{l}\text { Moho } \\
\text { Depth } \\
(\mathbf{k m})\end{array}$ & Source & Method \\
\hline \multirow{9}{*}{ Alborz } & The west of Alborz & 45 & Asudeh, [1982] & Surface and body waves \\
\hline & Central Alborz & 35 & $\begin{array}{l}\text { Dehghani and Makris, } \\
\text { [1984] }\end{array}$ & Gravity study \\
\hline & The west of Alborz & 36 & Tatar, [2001] & - \\
\hline & Tehran region & 34 & Ashtari et al., [2005] & Microseismicity \\
\hline & Tehran region & 46 & $\begin{array}{l}\text { Doloei and Roberts, } \\
\text { [2003] }\end{array}$ & - \\
\hline & The south of Alborz & $46-48$ & Radjaee et al., [2007] & Receiver functions \\
\hline & Central Alborz & 55 & Radjaee et al., [2007] & Receiver functions \\
\hline & The north of Alborz & 44 & Radjaee et al., [2007] & Receiver functions \\
\hline & $\begin{array}{l}\text { The Southern of the } \\
\text { Alborz Mountains }\end{array}$ & 47 & Rastgoo et al., [2018] & Joint inversion \\
\hline \multirow{11}{*}{ Zagros } & $\begin{array}{l}\text { The NW of Zagros } \\
\text { Mountains }\end{array}$ & 53 & Tunini, et al., [2015] & The LitMod-2D code ${ }^{1}$ \\
\hline & $\begin{array}{l}\text { The SW of Zagros } \\
\text { Mountains }\end{array}$ & 53 & Tunini, et al., [2015] & The LitMod-2D code \\
\hline & Beneath the NW Zagros & 42 & Afsari et al., [2011] & Teleseismic Ps converted phases \\
\hline & Beneath the SSZ & $55-63$ & Tunini, et a., [2015] & The LitMod-2D code \\
\hline & The North side of SSZ & 51 & Afsari et al., [2011] & Teleseismic Ps converted phases \\
\hline & The SW of Zagros & 50 & Motaghi, et al., [2014] & $\begin{array}{l}\text { Receiver functions and } \\
\text { fundamental mode Rayleigh } \\
\text { wave group velocity }\end{array}$ \\
\hline & $\begin{array}{l}\text { Beneath the Main Zagros } \\
\text { Fault }\end{array}$ & 60 & $\begin{array}{l}\text { Synder and Barzangi, } \\
\text { [1986] }\end{array}$ & $\begin{array}{l}\text { Modelling of the Bourguer } \\
\text { anomaly }\end{array}$ \\
\hline & $\begin{array}{l}\text { Beneath the } \\
\text { Mesopotamian foreland }\end{array}$ & 40 & $\begin{array}{l}\text { Synder and Barzangi, } \\
\text { [1986] }\end{array}$ & $\begin{array}{l}\text { Modelling of the Bourguer } \\
\text { anomaly }\end{array}$ \\
\hline & $\begin{array}{l}\text { The southwestern side of } \\
\text { SSZ }\end{array}$ & 56 & Paul et al., [2006, 2010] & $\begin{array}{l}\text { P Receiver function of } \\
\text { teleseismic earthquakes }\end{array}$ \\
\hline & $\begin{array}{l}\text { The Mesopotamian- } \\
\text { Persian Gulf foreland } \\
\text { basin }\end{array}$ & 42 & $\begin{array}{l}\text { Jimenez-Munt et al., } \\
\text { [2012] }\end{array}$ & $\begin{array}{l}\text { Fitting elevation and geoid } \\
\text { anomaly data combined with } \\
\text { thermal analysis. }\end{array}$ \\
\hline & Below the High Zagros & 60 & $\begin{array}{l}\text { Jimenez-Munt et al., } \\
\text { [2012] }\end{array}$ & $\begin{array}{l}\text { Fitting elevation and geoid } \\
\text { anomaly data combined with } \\
\text { thermal analysis. }\end{array}$ \\
\hline
\end{tabular}

${ }^{1}$ This code is developed by Afonso et al., [2008], which combines geophysical and petrological data, in order to study the crust and upper mantle structures from a thermal, compositional, seismological and density point of view (Tunini, et al., 2015).

Table 1. Results of studies dedicated to the Moho depth in the Alborz and Zagros regions. Abbreviations are: SSZ: Sanandaj-Sirjan Zone; ZFB: Zagros Folded Belt. 


\section{Reza Emami et al.}

Alborz and NW Zagros regions using the Single Backscattering (SBS) [Aki and Chouet, 1975] and Single Isotropic Scattering (SIS) [Sato, 1977] models. Then, obtained $Q_{\mathrm{c}}$ values using both vertical and horizontal components in the Alborz and NW Zagros regions are compared.

Many researchers [e.g., Rautian and Khalturin, 1978; Roecker et al., 1982], have been shown that the estimated Q-coda values at long lapse times (large epicentral distances) are greater than those for short lapse times (short epicentral distances). The dependence of $Q_{c}$ values on the coda window length and its variation with depth is another topic of interest that has been investigated in this study. Finally, our results are discussed and compared to other studies across the world and in Iran.

\section{Geology and tectonic setting of the study area}

The Iranian plateau is a relatively wide zone of compressional deformation along the Alpine-Himalayan active mountain belt, which is entrapped between two stable platforms, the Arabian plate in the southwest and the Turan platform (Eurasia) in the northeast [Mirzaei et al., 1998; Rahimi and Hamzehloo, 2008]. The Iranian Plateau, characterized by active faulting and folding, recent volcanic activities, mountainous terrain, and variable crustal thickness, has been frequently struck by earthquakes resulting in massive loss of life. The active tectonics of Iran is dominated by the northward motion of Arabia with respect to Eurasia [Ma'hood, 2014].

\subsection{Alborz}

The Alborz Mountains are located in northern Iran, parallel to the southern margin of the Caspian Sea. These Mountains are a still active collisional belt with 3-5 km topography, a length of $600 \mathrm{~km}$ in roughly E-W direction and a width of $100 \mathrm{~km}$ in N-S direction. They are surrounded by the Talesh Mountains in the west, Binalud and the KopetDagh mountains in the east, the South Caspian Basin in the north and central Iran in the south. Alborz is characterized by the dominance of platform-type sediments, including limestone, dolostone, and clastic rocks. Rock units from Precambrian to Quaternary have been identified, with some hiatuses and unconformities on Paleozoic and Mesozoic. Mesozoic sediments with a thickness of up to $3 \mathrm{~km}$ and 1-2 km of Cenozoic, mostly synorogenic sediments and volcanic activity throughout the Cenozoic, starting in Late Cretaceous, have covered its basement which includes Paleozoic sediments [Alavi, 1996].Volcanism is still sub-active as demonstrated by the quaternary activities around the highest mountain of the Alborz chain, the Damavand volcano. Two different kinds of relative motions control the tectonic activity of this belt [Ritz et al., 2006]: first, a generally compressive motion starting since about $7 \mathrm{Ma}$ (Million years) due to the northward convergence ( $5 \mathrm{~mm} / \mathrm{yr}$ ) of central Iran toward Eurasia [Vernant et al., 2004]; second, the northwestward motion of the South Caspian Basin with respect to Eurasia resulted in a sinistraltranspressional regime in the Alborz region (4 mm/yr left lateral shear) [Vernant et al., 2004]. However, the tectonic regime in the central Alborz seems to be changing to transtensional due to an acceleration of the northwestward movement of the South Caspian block which started since the middle Pleistocene [Masson et al., 2006; Ritz et al., 2006]. Previous studies [e.g., Asudeh, 1982; Dehghani and Makris, 1984; Tatar, 2001; Ashtari et al., 2005; Doloei and Roberts, 2003; Radjaee et al., 2007; Rastgoo et al., 2018] have described the crustal structure in the Alborz Mountains and reported different values for the Moho depth in Alborz based on different methods. According to these studies, the crustal thickness varies from $34 \mathrm{~km}$ in the Tehran region to $55 \mathrm{~km}$ beneath central Alborz (See Table 1 for more details).

Along the Alborz mountain belt, seismic activity occurs primarily in the upper crust but with some infrequent events in the lower crust, particularly in the western part of the belt which is called Talesh, where the South Caspian basin underthrusts NW Iran [Engdahl et al., 2006]. Teleseismic waveform modelling of moderate-sized earthquakes reveals centroid depths of up to $\sim 27 \mathrm{~km}$ in the western Alborz and Talesh [Jackson et al., 2002] and a few teleseismic locations [Engdahl et al., 2006] suggested some earthquakes were as deep as $25-30 \mathrm{~km}$ in the central and eastern Alborz.

Many large destructive historical earthquakes with magnitude greater than 7 have happened since the 4 th century B.C until 1830 in the Alborz region [Ambraseys and Melville, 1982]. For example, the Rudbar $\mathrm{M}_{\mathrm{w}} 7.3$ earthquake of 1990 June 20 at a depth of $18.5 \mathrm{~km}$, with $80 \mathrm{~km}$ left-lateral strike-slip motion was one of the largest and most destructive earthquakes (killed 13,000-40,000 people) to have occurred in Iran during the instrumental period [Berberian ad Walker, 2010]. 


\section{Variation of coda wave attenuation in the Alborz and NW Zagros regions}

\subsection{NW Zagros}

The Zagros fold belt is the result of the continued convergence between the Arabian and Eurasian plates, which has been in progress since the Miocene episode of continental collision [Stocklin, 1968; Falcon, 1974; Hessami and Jamali, 2006]. The Zagros fold belt with Northwest to Southwest trending of Iran (Almost 1,500 km in length and up to 300 $\mathrm{km}$ wide) is a major structural element of the Alpine-Himalayan belt. It is one of the most rapidly deforming and seismically active fold-and-thrust belts anywhere in the world [Vernant et al., 2004]. The Zagros region is one of the youngest and most active tectonic regions on Earth so that more than $50 \%$ of teleseismic recorded earthquakes in Iran have occurred in this region [Zamani and Agh-Atabai, 2011]. This area is home to some of the world's largest oil reservoirs and was the location of the initial continental collision between the Arabian and Eurasian plates. The area is generally composed of limestone with upper Pliocene units of sandstone [Molnar, 2006].

The NW-SE-trending Zagros mountain belt is divided into five different parallel structural domains, separated by major faults, from SW to NE: (1) the Mesopotamian-Persian Gulf Foreland Basin along the Euphrates and Tigris Plain and its continuation in the Persian Gulf, Formed by the flexure of the Arabian Plate in front of the Zagros fold-and-thrust belt (ZFTB), (2) The fold-and-thrust belt (or Simply Folded Belt) bounded by the Mountain Front Fault (MFF) from the foreland basin [Falcon, 1961; Berberian, 1995; Sepehr and Cosgrove, 2004; Emami et al., 2010] (3) the Imbricate Zone (IZ) (also called High Zagros Thrust Belt of Crush Zone), limited by the High Zagros Fault (HZF) [Berberian, 1995] to the southwest, is a highly deformed domain, involving multiple tectonic thrust sheets composed of sedimentary, radiolaritic and ophiolitic rocks, which represents the distal cover rocks of the Arabian Plate, (4) The metamorphic and magmatic Snandaj-Sirjan Zone (SSZ) separated from previous unit by the Main Zagros Fault (MZF). This zone is an Iranian continental block that is thrusted to the SW, on top of the MZF [e.g., Falcon, 1967; Stocklin, 1968], and (5) The Tertiary Urumieh-Dokhtar Magmatic Arc (UDMA) [Varges et al., 2011; Jimenez-Munt et al., 2012; Tunini et al., 2015].

Our study area is located in the northwestern edge of the Simply Folded Belt. The Zagros Simply Folded Belt is located to the south of the High Zagros Fault [Berberian, 1995; Khadivi, 2010). Unlike the other areas of Zagros which have active reverse faults [Berberian, 1995; Jackson and McKenzie, 1984; Nowroozi, 1972; Talebian and Jackson, 2004], the NW Zagros region, has a right lateral strike-slip motion which is confirmed by Fault-plane solutions [Mokhtari et al., 2004].

The strain rate calculated from the historical and recent earthquakes in Zagros is less than $10 \%$ of the expected Arabia-Eurasia convergence rate, which shows that $90 \%$ of the total deformation energy is being released by aseismic processes [Shoja-Taheri and Niazi, 1981; McKenzie, 1988; Ekstrom and England, 1989]. The responsible for the subdued seismic deformation in Zagros may be the existence of a plastic layer (the Hormoz formation) between the sedimentary column and the basement rock [Jackson and McKenzie, 1988]. Zagros contains a sedimentary cover that spans the entire Phanerozoic and is up to 10-15 km thick [e.g., O’Brien, 1957; James and Wynd, 1965; Stocklin, 1968; Falcon, 1969; Colman-Sadd, 1978]. With a mixture of strong platform carbonates and weaker evaporates, marls and shales, the stratigraphy has long been known to exert an important influence on the style of deformation.

The results show that compared to the Alborz region, the epicentral distribution in Zagros has a weak multifractal (i.e. less heterogeneous) structure. The two distinct multifractal distribution patterns in these regions reflect different underlying seismotectonic processes related to earthquake activity. Both the fact that, in Zagros, there are more small earthquakes than large ones and the relatively low level of discontinuous seismicity with the sporadic occurrence of strong destructive events in Alborz confirm that the Zagros region is relatively more homogeneous than Alborz [Zamani and Agh-Atabai, 2011].

During the last decades, the crustal thickness of the Zagros Mountain belt and its foreland basin has been the topic of numerous studies [Verges et al., 2011; Jimenz-Munt et al., 2012]. The results of several studies [Synder and Barzangi, 1986; Paul et al., 2006, 2010; Afsari et al., 2011; Jimenez-Munt et al., 2012; Motaghi, et al., 2014; Tunini, et al., 2015] obtained through several methods show that the crustal thickness varies from $35-45 \mathrm{~km}$ in the Mesopotamian Foreland and Arabian Platform to between 44-69 km below the Zagros Mountains with the maximum values beneath the SSZ zone [Tunini et al., 2015]. See Table 1 for more details.

Results of reliable waveform modeling [e.g., Jackson and McKenzi, 1984; Ni and Barazangi, 1986; Baker et al.,1993] and microearthquake studies [e.g., Von Dollen et al., 1997; Savage et al., 1977; Niazi et al.,1978] show that the large earthquakes in Zagros usually nucleate at depths of $8 \sim 15 \mathrm{~km}$. These studies not only failed to reveal activity deeper than $20 \mathrm{~km}$ in Zagros [Mirzaei et al., 2014] but also are confirmed by local seismograph networks observations [Tatar et al., 2004]. Actually, there is no reliable evidence for subcrustal events [Ni and Barazangi, 1986; Mirzaei et al., 1998]. 


\section{Reza Emami et al.}

The earthquake of November 12, 2017, with a moment magnitude of 7.3 at an approximately $18 \mathrm{~km}$ depth, has been one of the most destructive earthquakes (436 people died according to the latest statistics published) over the past two decades to have happened in NW Zagros [Alavi et al., 2018].

\section{Data}

In this study, we use the three components waveforms recorded in 2011-2016 by seismic stations which belongs to the Iranian Seismological Center (IRSC) and the International Institute of Earthquake Engineering and Seismology (IIEES). The IRSC stations consisted of three components short-period and broadband velocity seismometers. The short period seismic stations are equipped with Kenimetrics SS-1 sensors, which their response is flat at the frequency band of 1-25 Hz. In the broad-band stations of IRSC which different seismometers such as Trillium-40s, Trillium-120s, and Güralp-CMG3EPS-120s have been employed, their response is flat at a frequency less than $50 \mathrm{~Hz}$. The broadband IIEES stations are equipped with Güralp CMG-3T seismometers, which their velocity response is flat at the frequency range of $0.0083-50 \mathrm{~Hz}$. The sampling rate of both IRSC and IIEES dataset which was used in this study is 50 samples/s. The details of these stations are provided in Table 2.

In the present study, 8717 seismograms of 677 local earthquakes (418 events in Alborz and 259 in NW Zagros) with magnitude $\mathrm{M}_{\mathrm{N}}$ between 3 and 5.7, were selected. The signal-to-noise ratio of selected seismograms is greater than 3.0. The distribution of seismic stations and events used in this study are shown in Figure 1.

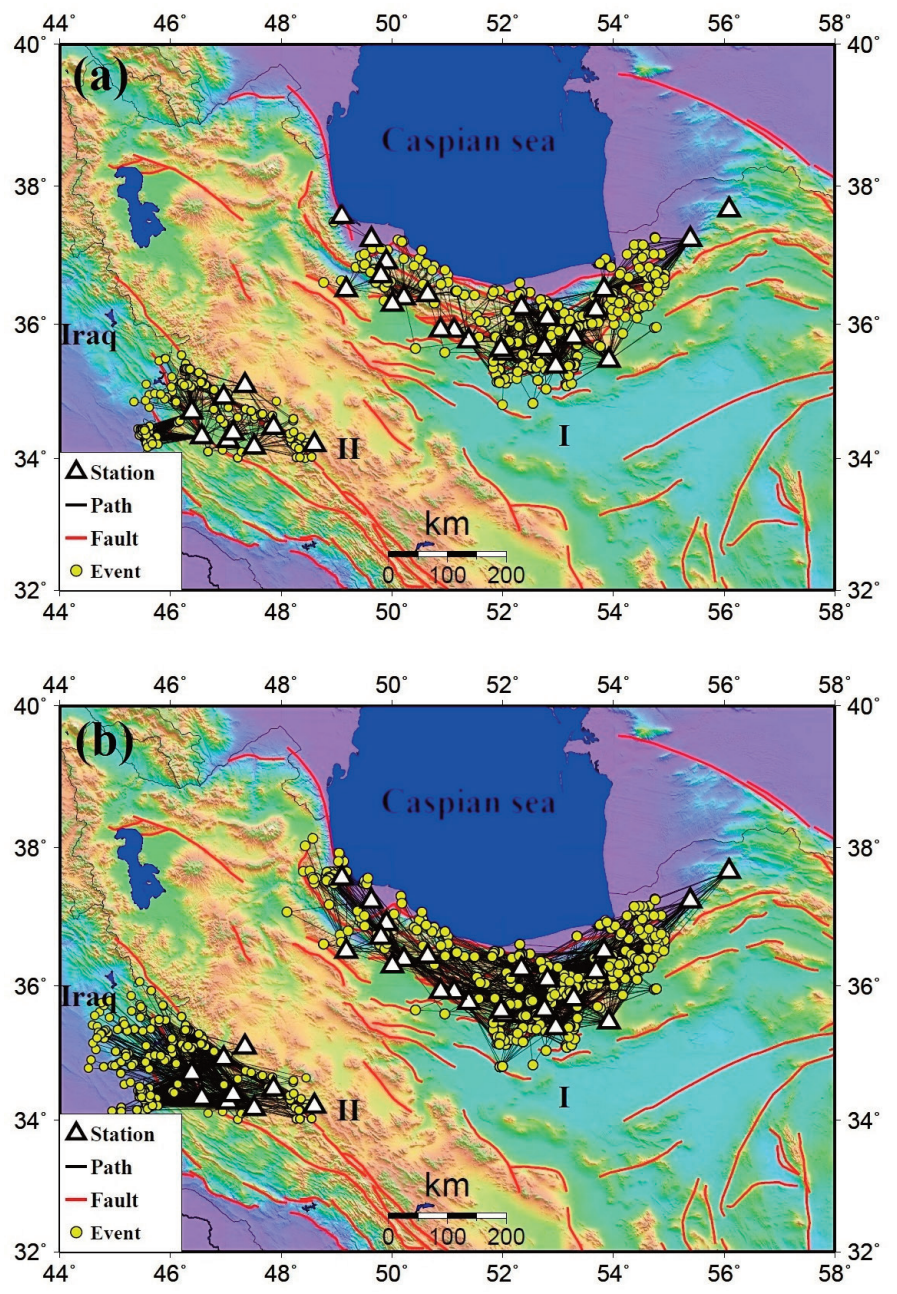

Figure 1. Distribution of ray paths (lines) between earthquakes (circles) and stations (triangles); a) for $\mathrm{R}<100 \mathrm{~km}$ and, b) for $100<\mathrm{R}<200 \mathrm{~km}$, I: Alborz; II: NW Zagros. 
As Figure 1 shows, 23 and 8 seismic stations are located in the Alborz and NW Zagros regions, respectively. By considering the epicentral distance, we grouped the dataset for $\mathrm{R}<100 \mathrm{~km}$ and $100<\mathrm{R}<200 \mathrm{~km}$, which hereafter will be called, dataset- 1 and dataset-2, respectively. The magnitude-distance distribution of our dataset is shown in Figure 2. Most of events which were used in this study, have shallow focal depth $(1.0 \leq \mathrm{h} \leq 20 \mathrm{~km})$, and the average focal depth is about $10 \mathrm{~km}$. Only a few earthquakes have focal depth of more than $20 \mathrm{~km}$, with the deepest earthquake of $\sim 28 \mathrm{~km}$ depth (Figure 2).
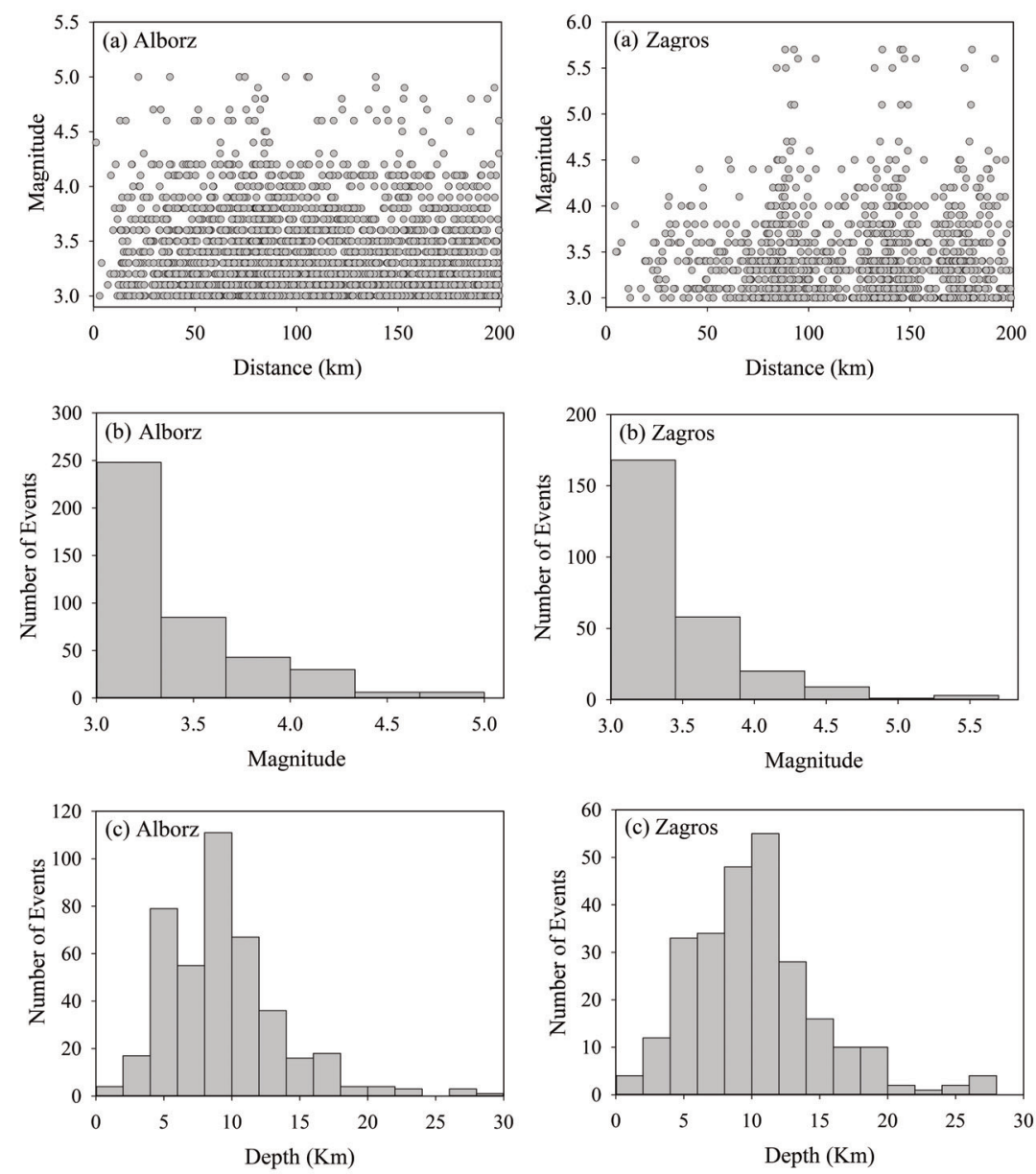

Figure 2. a) $M_{N}$ magnitude versus epicentral distance distribution, b) Histogram of the magnitude $\left(\mathrm{M}_{\mathrm{N}}\right)$ of the events, and c) Histogram of the depth of the events used in this study for two regions.

\section{Method of analysis}

\section{$4.1 Q_{c}$ estimation}

In this study, the SBS [Aki and Chouet, 1975] and SIS [Sato, 1977] methods have been used to estimate the coda wave attenuation.

\subsubsection{SBS method}

The generation and propagation of coda waves may be described by a single backscattering model. This mechanism was proposed by Aki [1969] and Aki and Chouet [1975] to describe the time dependence of the scattered energy density at the source location in the 3-D space [Tuve et al., 2006]. The single backscattering model [Aki and 
Reza Emami et al.

\begin{tabular}{|c|c|c|c|c|c|c|c|c|c|c|c|}
\hline $\begin{array}{c}\text { Station } \\
\text { Name }\end{array}$ & $\begin{array}{c}\text { Sensor } \\
\text { Type }\end{array}$ & $\begin{array}{c}\text { S.F } \\
(\mathrm{Hz})\end{array}$ & $\begin{array}{l}\text { Lon. } \\
\text { (Eo) }\end{array}$ & $\begin{array}{l}\text { Lat. } \\
\text { (No) }\end{array}$ & $\begin{array}{l}\boldsymbol{Q}_{0} \pm \sigma \\
(\mathrm{SBS})\end{array}$ & $\begin{array}{c}\mathbf{n}^{ \pm} \boldsymbol{\sigma} \\
(\mathrm{SBS})\end{array}$ & $\begin{array}{l}\boldsymbol{Q}_{0} \pm \sigma \\
(\mathrm{SIS})\end{array}$ & $\begin{array}{l}n \pm \sigma \\
(S I S)\end{array}$ & $\begin{array}{c}\text { A.D } \\
(\mathrm{km})\end{array}$ & No. & $\mathbf{R}^{2}$ \\
\hline \multicolumn{12}{|c|}{ Station (Alborz) } \\
\hline ALA & SS1 & 50 & 52.810 & 36.083 & $107 \pm 10$ & $0.89 \pm 0.06$ & $111 \pm 11$ & $0.89 \pm 0.06$ & 55 & 95 & 0.9717 \\
\hline ANJ & SS1 & 50 & 53.915 & 35.468 & $119 \pm 9$ & $0.85 \pm 0.05$ & $122 \pm 10$ & $0.86 \pm 0.05$ & 78 & 80 & 0.9811 \\
\hline $\mathrm{CHTH}^{*}$ & CMG_3T & 50 & 51.126 & 35.908 & $152 \pm 17$ & $0.77 \pm 0.07$ & $159 \pm 19$ & $0.76 \pm 0.07$ & 80 & 13 & 0.9501 \\
\hline CSN1 & T40_40 & 50 & 49.095 & 37.564 & $46 \pm 2$ & $1.01 \pm 0.03$ & $46 \pm 2$ & $1.01 \pm 0.03$ & 22 & 7 & 0.9956 \\
\hline DAMV* & CMG_3T & 50 & 51.971 & 35.630 & $112 \pm 10$ & $0.90 \pm 0.05$ & $112 \pm 11$ & $0.92 \pm 0.06$ & 64 & 25 & 0.9778 \\
\hline DMV & SS1 & 50 & 52.032 & 35.577 & $104 \pm 7$ & $0.88 \pm 0.04$ & $107 \pm 8$ & $0.89 \pm 0.04$ & 56 & 69 & 0.9855 \\
\hline FIR & T120_40 & 50 & 52.754 & 35.642 & $113 \pm 9$ & $0.85 \pm 0.05$ & $115 \pm 9$ & $0.86 \pm 0.05$ & 62 & 118 & 0.9768 \\
\hline GIDE* $^{*}$ & CMG_3T & 50 & 49.900 & 36.910 & $167 \pm 14$ & $0.67 \pm 0.05$ & $179 \pm 16$ & $0.65 \pm 0.05$ & 33 & 1 & 0.9644 \\
\hline GLO & SS1 & 50 & 53.831 & 36.502 & $98 \pm 2$ & $0.91 \pm 0.01$ & $101 \pm 2$ & $0.90 \pm 0.01$ & 70 & 135 & 0.9981 \\
\hline GZV & SS1 & 50 & 50.218 & 36.386 & $118 \pm 13$ & $0.79 \pm 0.06$ & $123 \pm 14$ & $0.78 \pm 0.07$ & 71 & 31 & 0.9571 \\
\hline JIR1 & T40_40 & 50 & 49.802 & 36.708 & $102 \pm 12$ & $0.95 \pm 0.07$ & $101 \pm 12$ & $0.95 \pm 0.07$ & 42 & 4 & 0.9654 \\
\hline KIA & SS1 & 50 & 53.684 & 36.207 & $111 \pm 6$ & $0.79 \pm 0.03$ & $113 \pm 8$ & $0.79 \pm 0.04$ & 62 & 31 & 0.9873 \\
\hline LAS & SS1 & 50 & 52.959 & 35.381 & $114 \pm 9$ & $0.86 \pm 0.05$ & $117 \pm 9$ & $0.86 \pm 0.05$ & 64 & 55 & 0.9803 \\
\hline MND & T120_40 & 50 & 55.389 & 37.237 & $126 \pm 4$ & $0.80 \pm 0.02$ & $128 \pm 4$ & $0.82 \pm 0.02$ & 78 & 37 & 0.9969 \\
\hline MRVT $^{*}$ & CMG_3T & 50 & 56.089 & 37.659 & - & - & - & - & - & - & - \\
\hline PRN & SS1 & 50 & 52.338 & 36.242 & $110 \pm 9$ & $0.92 \pm 0.05$ & $112 \pm 10$ & $0.92 \pm 0.05$ & 59 & 82 & 0.9788 \\
\hline QALM & GESP_DM & 50 & 50.646 & 36.432 & $107 \pm 9$ & $0.83 \pm 0.05$ & $112 \pm 10$ & $0.82 \pm 0.05$ & 68 & 20 & 0.9731 \\
\hline QCNT & GESP_DM & 50 & 50.009 & 36.290 & $139 \pm 22$ & $0.74 \pm 0.09$ & $143 \pm 24$ & $0.74 \pm 0.10$ & 55 & 8 & 0.8949 \\
\hline QSDN & GESP_DM & 50 & 49.174 & 36.290 & $99 \pm 9$ & $0.83 \pm 0.06$ & $104 \pm 10$ & $0.83 \pm 0.06$ & 55 & 6 & 0.9688 \\
\hline RST1 & T40_40 & 50 & 49.630 & 37.232 & - & - & - & - & - & - & - \\
\hline SHM & SS1 & 50 & 53.284 & 35.806 & $93 \pm 7$ & $0.90 \pm 0.04$ & $95 \pm 7$ & $0.90 \pm 0.04$ & 51 & 97 & 0.9841 \\
\hline TEH & T40_40 & 50 & 51.389 & 35.752 & $84 \pm 10$ & $1.23 \pm 0.12$ & $88 \pm 11$ & $1.23 \pm 0.12$ & 68 & 19 & 0.9655 \\
\hline THKV* & CMG_3T & 50 & 50.879 & 35.916 & $153 \pm 13$ & $0.78 \pm 0.05$ & $162 \pm 15$ & $0.77 \pm 0.05$ & 85 & 7 & 0.9699 \\
\hline \multicolumn{12}{|c|}{ Station (Zagros) } \\
\hline BZA & $\mathrm{T} 120 \_40$ & 50 & 47.861 & 34.470 & $86 \pm 4$ & $0.83 \pm 0.03$ & $90 \pm 4$ & $0.82 \pm 0.03$ & 50 & 23 & 0.9924 \\
\hline DHR & T120_40 & 50 & 46.387 & 34.700 & $115 \pm 11$ & $0.90 \pm 0.05$ & $119 \pm 11$ & $0.89 \pm 0.06$ & 75 & 125 & 0.9744 \\
\hline GHG & SS1 & 50 & 46.568 & 34.329 & $106 \pm 7$ & $0.93 \pm 0.04$ & $110 \pm 7$ & $0.93 \pm 0.04$ & 85 & 95 & 0.9885 \\
\hline HSAM & T40_40 & 50 & 48.602 & 34.212 & $93 \pm 4$ & $0.72 \pm 0.03$ & $97 \pm 4$ & $0.71 \pm 0.03$ & 43 & 12 & 0.9911 \\
\hline $\mathrm{KCHF}$ & T40_40 & 50 & 47.040 & 34.275 & $124 \pm 10$ & $0.59 \pm 0.05$ & $124 \pm 11$ & $0.60 \pm 0.05$ & 63 & 14 & 0.9533 \\
\hline KER & SS1 & 50 & 47.133 & 34.387 & $121 \pm 14$ & $0.53 \pm 0.07$ & $127 \pm 15$ & $0.52 \pm 0.07$ & 83 & 18 & 0.8912 \\
\hline KOM & $\mathrm{T} 40 \_40$ & 50 & 47.514 & 34.176 & $86 \pm 6$ & $0.82 \pm 0.04$ & $89 \pm 6$ & $0.82 \pm 0.04$ & 62 & 18 & 0.9831 \\
\hline LIN & T120_40 & 50 & 46.963 & 34.919 & $116 \pm 7$ & $0.66 \pm 0.03$ & $118 \pm 7$ & $0.67 \pm 0.04$ & 66 & 37 & 0.9814 \\
\hline SNGE* & CMG_3T & 50 & 47.347 & 35.093 & $119 \pm 12$ & $0.74 \pm 0.06$ & $124 \pm 13$ & $0.73 \pm 0.06$ & 82 & 11 & 0.9557 \\
\hline
\end{tabular}

Stations marked with * belong to the IIEES.

Table 2 . The quality factor at reference frequency $1 \mathrm{~Hz}$, that is, $Q_{0}$, attenuation parameter, $\mathrm{n}$, and the result of statistical analysis including correlation coefficients, $\mathrm{R}^{2}$, and standard deviations (presented after \pm ) for epicentral distance range of $0-100 \mathrm{~km}$ and coda window length of $25 \mathrm{~s}$ for the SBS and SIS methods, vertical component. Abbreviations are: S.F: Sampling Frequency (Hz); A.D: Average Distance (km); No: Number of Rays. 
Chouet, 1975] has been widely used to estimate the attenuation of coda wave $Q_{c}^{-1}$ [Rautian and Khalturin, 1978; Roecker et al., 1982; Pulli, 1984] by using local network data. This model is based on the assumption that the source of the earthquake and the receivers are located at the same point in an infinite medium [Ugalde et al., 2002]. According to the SBS model, the coda waves are interpreted as backscattered body waves generated by numerous heterogeneities present in the Earth's crust and upper mantle [Ma'hood, 2014]. The coda amplitudes, $A(f, t)$, in a seismogram can be expressed for a central frequency $f$ over a narrow bandwidth signal, as a function of the lapse time $t$, measured from the origin time of the seismic event, as:

$$
A_{c}\left(f, t_{c}\right)=S(f) t_{c}^{-\alpha} \exp \left(\frac{-\pi f t_{c}}{Q_{c}(f)}\right)
$$

Where $f$ is the frequency, $\alpha$ is the geometrical spreading parameter which is considered one of values among 1.0, 0.5 or 0.75 for body waves, surface waves or diffusive waves, respectively [Sato and Fehler, 1998], $S(f)$ is the coda source function at frequency $f$ and is considered a constant, $t_{c}$ is the lapse time and $Q_{c}$ is the quality factor for coda waves. The amplitude of the coda wave, $\mathrm{A}_{c}\left(f, t_{c}\right)$, is calculated using the envelope function of the coda amplitude by applying the Hilbert transform according to the following formula:

$$
A_{c}\left(f, t_{c}\right)=\sqrt{\left[x\left(f, t_{c}\right)\right]^{2}+\left[H\left(x\left(f, t_{c}\right)\right)\right]^{2}}
$$

In which $x\left(f, t_{c}\right)$ is the amplitude of the band-pass-filtered coda waves with central frequency $f$ at lapse time $t_{c}$ and $\mathrm{H}$ is the Hilbert transform function. The low cut-off and high cut-off for nine passbands with a bandwidth $0.667 f$ are given in Table 3. Coda window seismograms are usually smoothed by applying Root-Mean-Square (RMS) techniques to each envelope [Havskov et al., 1989). Using the coda decay envelope is the most commonly used approach for estimating coda $Q$ [e.g., Woodgold, 1994; Rahimi et al., 2010; Farrokhi et al., 2015; Sedaghati and Pezeshk, 2016a, Hovskov et al., 2016].

\begin{tabular}{cccc} 
Band & Low cut-off Frequency $(\mathbf{H z})$ & Central Frequency $(\mathbf{H z})$ & High cut-off Frequency $(\mathrm{Hz})$ \\
\hline 1 & 0.67 & 1.00 & 1.33 \\
\hline 2 & 1.00 & 1.5 & 2.00 \\
\hline 3 & 1.33 & 2.0 & 2.67 \\
\hline 4 & 2.00 & 3.0 & 4.00 \\
\hline 5 & 2.67 & 4.0 & 5.33 \\
\hline 6 & 4.00 & 6.0 & 8.00 \\
\hline 7 & 5.33 & 8.0 & 10.67 \\
\hline 8 & 8.00 & 12.0 & 16.00 \\
\hline 9 & 10.67 & 16.0 & 21.33 \\
\hline
\end{tabular}

Table 3. Central frequency components of band-pass filter with low and high cut-off frequencies.

The equation (1) is valid at lapse times (measured from the earthquake origin time) of approximately $t>2 t_{s}$, in which $t_{s}$ is the travel time of the direct S-wave [Rautian and Khalturin, 1978]. $Q_{c}^{-1}(f)$ can be easily estimated from the recorded seismograms, by fitting the envelopes of the filtered and smoothed seismic traces to the Eq. (1) over a specified time window $t_{1} \leq t \leq t_{2}$ [Aki and Chouet, 1975; Tuve et al., 2006; Woong Chung et al., 2009]. The start of the time window is taken as $t_{1}=2 t_{s}$ and the end of the time window, $t_{2}$, is $2 t_{s}+\mathrm{W}$, which $\mathrm{W}$ represents the coda window length. 


\section{Reza Emami et al.}

In general, $\alpha$ is assumed to be 1.0 for a short distance within $100 \mathrm{~km}$ when the direct $\mathrm{Pg}$ and $\mathrm{Sg}$ phases arrive, and 0.5 for a distance beyond $100 \mathrm{~km}$ when $\mathrm{Lg}$ and surface waves are dominant [Chun et al., 1987; Shin and Hermann, 1987; Petukhin et al., 2003]. Most researchers regarded $\alpha$ to be a constant beyond $100 \mathrm{~km}$ [e.g., Rogers et al., 1987; Brockman and Bollinger, 1992; Kumar et al., 2005; Mukhopadhyay et al., 2006; Rahimi et al., 2010; Farroki et al., 2015; Sedaghati and Pezeshk, 2016a; Dobrynina et al., 2017]. Other researchers treated $\alpha$ to be a variable depending on the propagation distance [e.g., Atkinson 2004; Singh et al., 2004; Calvet and Margerin, 2013; Galluzzo et al., 2015; De Siena et al., 2016; Havskov et al., 2016], in which most of them used the multiple scattering method for estimating of coda $Q$. In this work, the coda window lengths up to $60 \mathrm{~s}$ have been used by applying the single scatting method. Therefore, putting $\alpha=1$ and taking a natural logarithm from both sides of Eq. (1), gives:

$$
\ln \left[A_{c}\left(f, t_{c}\right) t_{c}\right]=c-b t_{c}
$$

Where $b$ and $c$ are equal to $-\pi f / Q_{c}$ and $\ln (S(f))$, respectively. The slope of the linear-squares fit between $\ln \left[A(f, t)^{*} t\right]$ and $t$ yields the $Q$ value for a specific frequency and lapse time window (Figure 3 ).
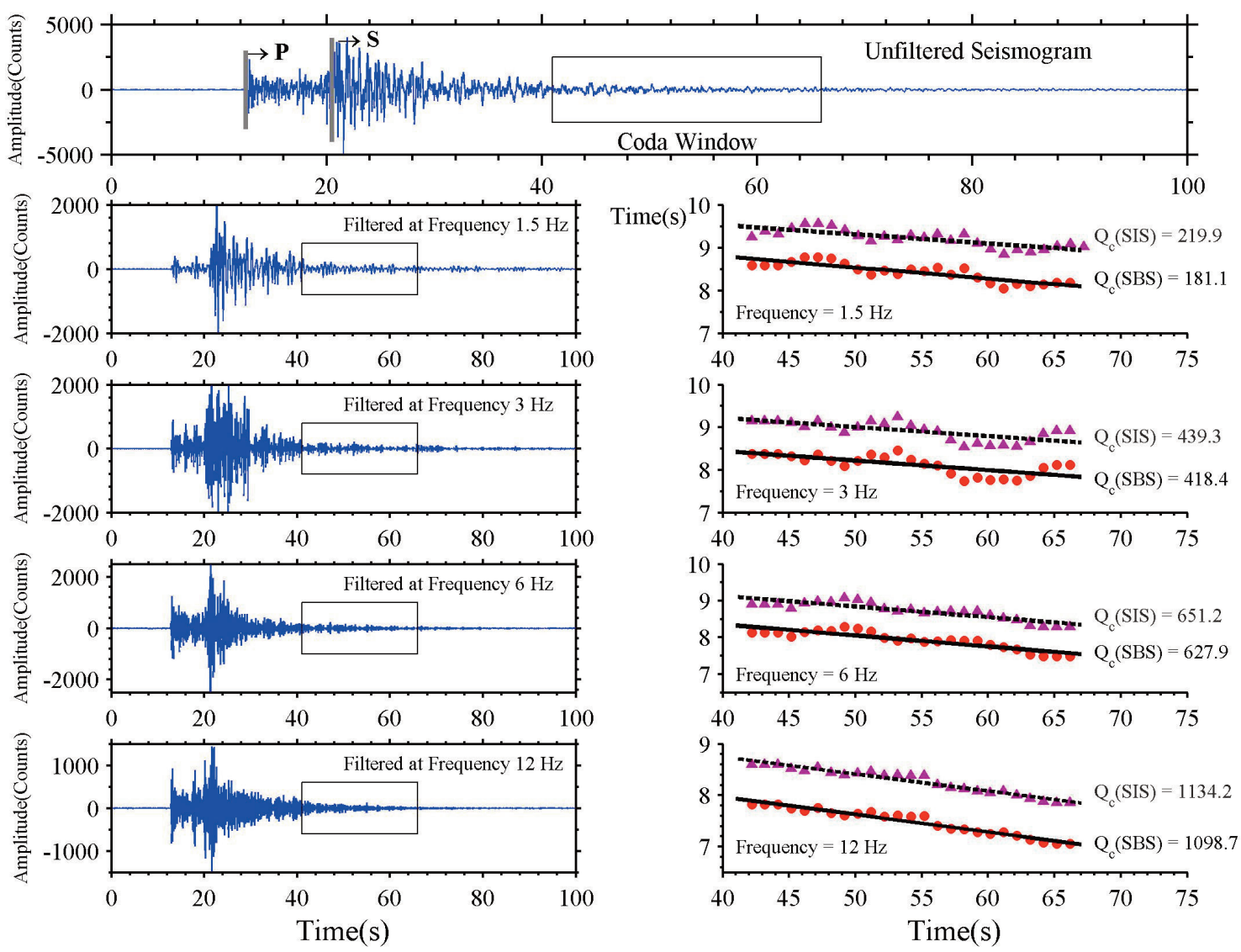

Figure 3. Figure showing an original seismogram (upper panel) for the 20 March 2014 earthquake $\left(36.95^{\circ} \mathrm{N}, 50.49^{\circ} \mathrm{E} ; \mathrm{M}\right.$ 3.6; and $\sim 16 \mathrm{~km}$ depth) recorded at the station GZV (vertical component) with an epicentral distance of around $66 \mathrm{~km}$ for estimation of $Q_{c}$. The four left-hand panels show the band-pass-filtered seismograms at central frequencies of $1.5,3,6$, and $12 \mathrm{~Hz}$, respectively. The corresponding right-hand panels show the variation of $\operatorname{Ln}\left(\mathrm{A}_{\mathrm{c}}\right.$ $(f, t) . \mathrm{t})$ and $\operatorname{Ln}\left(\mathrm{A}_{\mathrm{c}}(f, t) \cdot \mathrm{r} / \sqrt{\mathrm{K}}(\mathrm{a})\right)$ for the single backscattering (SBS) (circles) and single isotropic-scattering (SIS) (triangle) methods, respectively versus time(s). Solid and dashed lines show the least-square-fitted line at each frequency band for SBS and SIS data, respectively. Abbreviations are: P: P-wave time; S: S-wave time. 


\section{Variation of coda wave attenuation in the Alborz and NW Zagros regions}

\subsubsection{SIS Method}

The SBS method assumes that the source of the earthquake and the receiver are coincident; therefore, it holds, empirically, for $t>2 t_{s}$, where $t_{s}$ is the $S$ wave travel time [Rautian and Khalturin, 1978]. Sato [1977] developed the SIS model that considers the case of non-coincident source and receiver, thus allowing one to begin the coda analysis just after the $S$ wave arrival. In this model, spherical radiation and isotropic scattering are assumed, and the random distribution of scatters is considered to be homogeneous and isotropic [Ugalde et al., 2002]. The SIS model is particularly important when one is restricted to measurements of coda waves close to the S-wave arrival. For example, in seismically noisy locations the coda wave amplitudes at times greater than twice the S-wave travel time are often less than the background noise level, for small events [Novelo-Casanova and Lee, 1991]. Here, in order to comparison, the same starting point for coda window (2ts) is used in both methods, however, the quality of data (SNR) was good even using $t_{s}$ for starting point in the SIS method. Hence, the natural logarithm of the coda wave envelope is estimated as follows:

$$
\ln \left[\frac{A_{c}\left(f, t_{c}\right) r}{\sqrt{K(a)}}\right]=\ln (S(f))-\frac{\pi f t_{c}}{Q_{c}(f}
$$

where $A_{c}\left(f, t_{c}\right)$ represents the observed root-mean-square (RMS) amplitude of the narrow band-pass-filtered waveforms with central frequency $f, r$ is the source-receiver distance, $t_{c}$ is the lapse time measured from the origin time of the earthquake, $k(r, a)=(1 / r) K(a)^{0.5}, K(a)=(1 / a) \ln [(a+1) /(a-1)],(a>1)$ and $a=t_{d} / t_{s}$ and $S(f)$ is a constant. The attenuation of coda waves, $Q_{c}{ }^{-1}$, can be easily estimated from the slope of the straight line fitting the measured $\ln \left[A_{c}\left(f, t_{c}\right) / k(r, a)\right]$ versus $t$ for a given central frequency (Figure 3) [Rautian and Khalturin, 1978].

\section{Results}

\subsection{Lateral variation of $Q_{0}$ in Alborz and NW Zagros}

The vertical and horizontal $Q$-factor values have been estimated at each station for 10 frequency bands from the SBS and SIS models so as to investigate the lateral variation of the uppermost part of the lithosphere attenuation structure in our study area which includes two tectonically different regions. Then the frequency-dependent equations of coda quality factor values have been obtained from the power-law equation. The estimated parameters from the power-law equation including the quality factor at reference frequency $1.0 \mathrm{~Hz}$, that is, $Q_{0}$, the frequency dependent parameter, $n$, and the result of statistical analysis, which include correlation coefficients and standard deviations, are presented in Table 2.

Medium heterogeneity and the small-scale lateral variations in the medium characteristic are expected to be more common in the upper lithosphere [Rahimi et al., 2010; Irandoust et al., 2015]. So, we concentrated on the study of coda waves at shorter coda window lengths and for smaller epicentral distances, because they are less affected by deeper parts of the lithosphere, and the heterogeneity of the upper lithosphere is better manifested in them.

Thus, datasets including the epicentral distance range of $0-100 \mathrm{~km}$ are selected for each station and $Q_{c}$ for the coda window length of $25 \mathrm{~s}$ was estimated using the SBS and SIS methods. Because of, the observed lateral variation might be due to the difference in the average epicentral distance of the recorded earthquakes in each station. Therefore, besides $Q_{c}$ at each station, the average epicentral distance has been reported in Table 2. Comparison of the results shows that the obtained $Q_{0}$ values using the SIS method are slightly larger than those values obtained by the SBS method (Table 2).

A comparison of the $Q_{0}$ values obtained from the data in 23 stations of the Alborz region (triangles in I region in Figure 1) shows that the estimated $Q_{0}$ values are not uniform. The maximum $Q_{0}$ value (=153) is observed in one of the IIEES stations (THKV) located at the southern border of Alborz, whereas the minimum $Q_{0}$ value $(=46)$ is seen at the station CSN1 located in the western border of the region and a moderate $Q_{0}$ value $(=98)$ is seen in the GLO at the northern border of Alborz. 


\section{Reza Emami et al.}

The variation of $Q_{0}$ values may be due to the differences either in the geological environment or the lithospheric structure in the region. However, in order to discuss the existence of such differences in Alborz, we should be certain that the average epicentral distance of each dataset is the same. So, it is necessary to check the distance parameter because the rays that propagate to longer distances penetrate into greater depths where the attenuation might be different and as a result, two stations with similar attenuation properties could show different $Q_{0}$ if one receives rays from a different distance. As shown in Table 2, there is a rough systematic variation between the average distance and $Q_{0}$ at all stations except for station GIDE, as the larger $Q_{0}$ values belong to stations that recorded more distant events. For example, the station CSN1 with lowest $Q_{0}$ has an average distance of $22 \mathrm{~km}$ and the station THKV with highest $Q_{0}$ in this study has an average distance of $85 \mathrm{~km}$ (that is the maximum average epicentral distance among the stations). In station GIDE the coda- $Q$ has estimated using just a single record and so cannot be reliable. Consequently, it can be said that the observed lateral variation in Alborz is mainly due to the difference in dataset properties. This result is in good agreement with the obtained result for the Central Alborz region by Rahimi et al. [2010]. The calculated $n$ value indicates a very strong frequency dependence of $Q_{c}$ in the Tehran (TEH) station. As mentioned earlier, coda waves are assumed as backscattered body waves generated by the numerous heterogeneities distributed randomly in the Earth's crust and upper mantle. Figure 1 shows that the ray coverage of TEH station is nearly uniform. Therefore, the higher value of $n$ for the coda quality factor may be caused by the direct influence of high heterogeneity level [Langston, 2003] of the Earth's crust and the upper mantle in the Tehran region on coda waves. This area has been confirmed by the dominant existence of folded structures and left-lateral strike-slip and thrust faults parallel to mountain belt trending towards E-W [Jackson et al., 2000; Allen et al., 2003].

Table 2 shows that the average $Q_{0}$ value for stations (Except DHR, KER, KCHF, and SNGE) in the Zagros equal or less than the average value for the Alborz region. There is also a rough systematic distance dependency in average $Q_{0}$ values for stations of NW Zagros. Hence, we are convinced that the differences in $Q_{0}$ values between stations reflect the properties of the dataset, however, the geological effect of the seismic station and ray path is undeniable.

\subsection{Attenuation variation with depth}

The coda quality factor represents the average attenuation property of an ellipsoidal volume with the source and receiver as its focus and depth as its height [Sedaghati and Pezeshk, 2016a]. The size of the study area depends on the epicentral distance and the focal depth of the earthquake, as well as on the coda window length.

The seismic wave attenuation and the frequency parameter $(n)$ are also dependent on the coda window length, such that as the coda window length increases, the quality factor increases and the frequency parameter decreases [Aki and Chouet, 1975; Kopnichev, 1991; Rautian and Khalturin, 1978, Sedaghati and Pezeshk, 2016a]. Numerous studies in different regions of the world illustrate that as the coda window length increase, so does $Q_{c}$ [Havskov et al., 1989, Gupta et al., 1998, Kumar et al., 2005; Rahimi et al., 2010]. As the epicentral distance and the coda window length increase, the deeper areas of the lithosphere play a role in the formation of the coda waves because the waves arriving later in the seismogram can be reflected from the deeper parts of the lithosphere than those arriving earlier. Therefore, by changing the coda window length, it can be examined the behaviour of $Q_{c}(f)$ as a function of the volume of the presumed region of coda formation and its maximum depth. Thus, that can be interpreted as an increase in the quality factor by increasing depth. Hence, in order to investigate the variation of attenuation with depth, the $Q_{c}$ value was estimated for 11 coda window lengths, which are taken from 10 to $60 \mathrm{~s}$ with an increment of $5 \mathrm{~s}$.

In the present study, the obtained results show that the coda seismic quality factor strongly depends on the frequency and coda window length. For example, the $Q_{c}$ values obtained from the Z component and the SBS method increases from 60.5 to 1025.7 for central frequencies of 1.0 and $16.0 \mathrm{~Hz}$ at a coda window length $\mathrm{W}=10 \mathrm{~s}$ and from 140.7 to 1132.6 at the same frequencies at $\mathrm{W}=60 \mathrm{~s}$ for the Alborz region, from 58.4 to 911.8 for central frequencies of 1.0 and $16.0 \mathrm{~Hz}$ at a coda window length $\mathrm{W}=10 \mathrm{~s}$ and from 153.9 to 1356.8 at the same frequencies at $\mathrm{W}=60 \mathrm{~s}$ for the Zagros region for dataset- 1 (Figure 4). The $Q_{c}$ increases from 68.4 to 1134.0 for central frequencies of 1.0 and $16.0 \mathrm{~Hz}$ at a coda window length $\mathrm{W}=10 \mathrm{~s}$, and from 207.7 to 1345.6 at the same frequencies at $\mathrm{W}=60 \mathrm{~s}$ for the Alborz region. It also increases from 62.4 to 1267.5 for central frequencies of 1.0 and $16.0 \mathrm{~Hz}$ at a coda window length $\mathrm{W}=10$ $\mathrm{s}$ and from 177.2 to 1511.6 at the same frequencies at $\mathrm{W}=60 \mathrm{~s}$ for the Zagros region for dataset-2 (Figure 4).

Despite that the attenuation of seismic waves has been the subject of several studies around the world, its dependence on frequency is still unclear [Dobrynina et al., 2017]. According to Aki and Chouet, [1975], the quality 

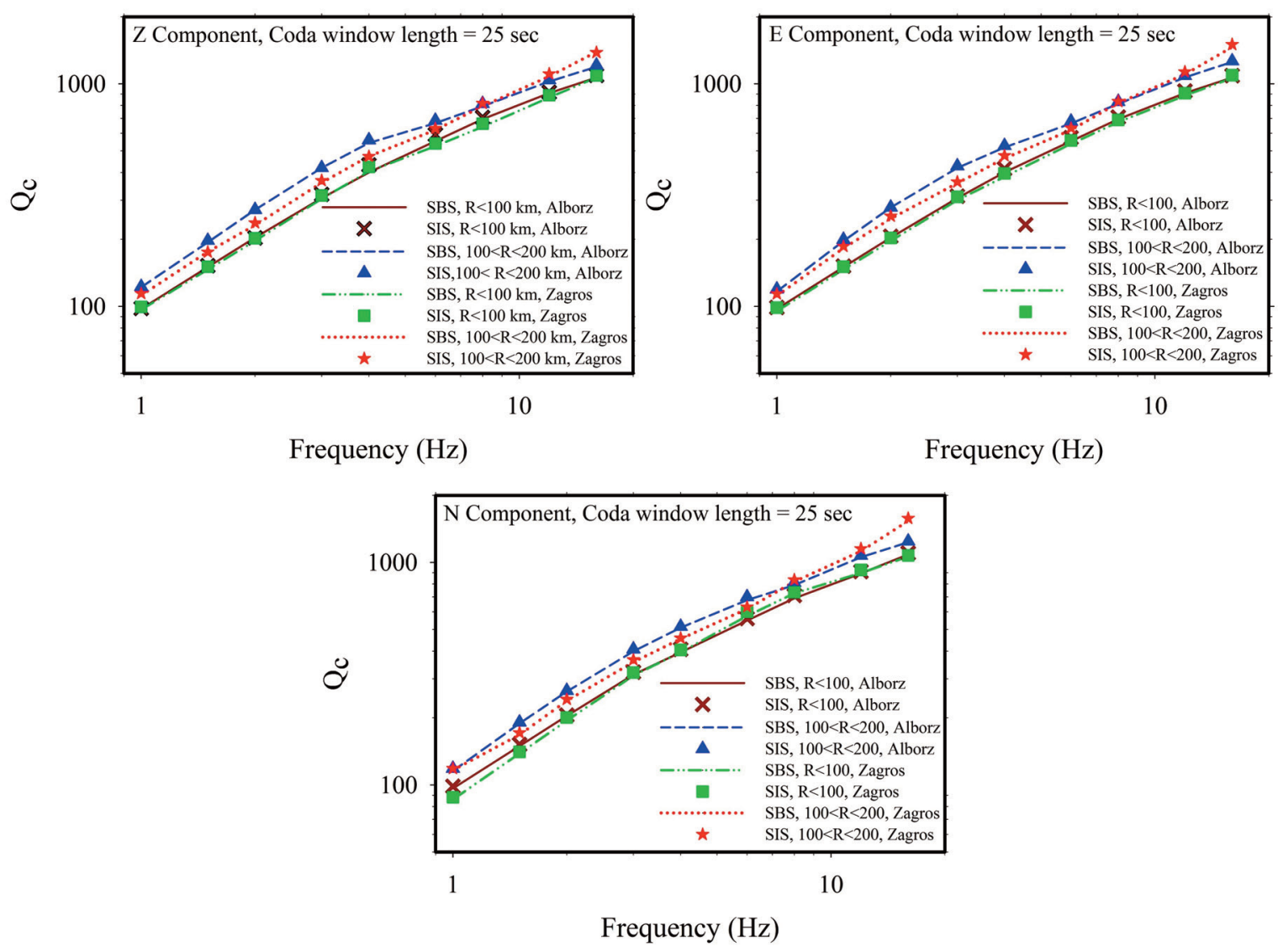

Figure 4. The plot of $Q_{c}$ values as a function of frequency obtained at $25 \mathrm{sec}$ lapse time window for Alborz and NW Zagros regions for 1) SIS and SBS methods, 2) epicentral distance ranges including $\mathrm{R}<100 \mathrm{~km}$ and $100<\mathrm{R}<200 \mathrm{~km}$, and 3) different components.

factor variations with frequency are related to heterogeneities that are randomly distributed in the lithosphere [Dobrynina et al., 2017]. For example, low-frequency signals with longer wavelength are not affected by the small scale heterogeneities [Furumura and Kennett, 2008]. There is a relationship between the frequency dependence of the quality factor and tectonic activity and age of the crust [Mak et al., 2004; Sato and Fehler, 1988].

In addition to the coda window length, the epicentral distance parameter has also been used to check the variations of the coda quality factor with depth, because the stations at shorter epicentral distances sample the coda waves from shorter zones while those at greater epicentral distances cover a larger and deeper area [Rahimi et al., 2010]. Therefore, the data were divided into two datasets based on the epicentral distances $R<100 \mathrm{~km}$ (dataset1) and $100 \mathrm{~km}<\mathrm{R}<200 \mathrm{~km}$ (dataset-2). Then, to study the attenuation properties of the study areas with depth in more details the $Q_{\mathrm{c}}$ values were estimated from different coda window lengths. The obtained results from various coda windows for the vertical and horizontal components are presented in Tables 4 to 6, respectively. The variation of the average $Q_{0}\left(Q_{c}\right.$ in $\left.1.0 \mathrm{~Hz}\right)$ and $n$ parameters with the coda window length in Alborz and in NW Zagros using the two datasets are shown in Figures 5 and 6 . The $Q_{0}$ value and the frequency-dependent parameter $(n)$ have an inverse behaviour (Figures 5 and 6).

Additionally, studies show that as the lapse time increases, so does $Q_{0}$ [Rocker et al., 1982; Pull, 1984; Woodgold, 1994; Zelt et al., 1999; Sertçelik, 2011]. Figure 5 (left panel) shows the variation of $Q_{0}$ with the coda window length in the first dataset, $R<100 \mathrm{~km}$, for both regions. It is observed that the studied regions have similar $Q_{0}$ values, of course, in Alborz are slightly higher than those in NW Zagros. This means that the crustal layers of the NW Zagros region are slightly more attenuative than the Alborz region. The increase rate of $Q_{0}$ for the coda window lengths of less than $45 \mathrm{~s}$ are similar for both regions. On the other hand, $Q_{0}$ values in $10-45 \mathrm{~s}$ increase uniformly for both regions. Figure 5 (right panel) shows the variation of $Q_{0}$ with the coda window length for the second dataset, $100<\mathrm{R}<200 \mathrm{~km}$. This Figure shows that the $Q_{0}$ values observed for Alborz are larger than those in NW Zagros and 


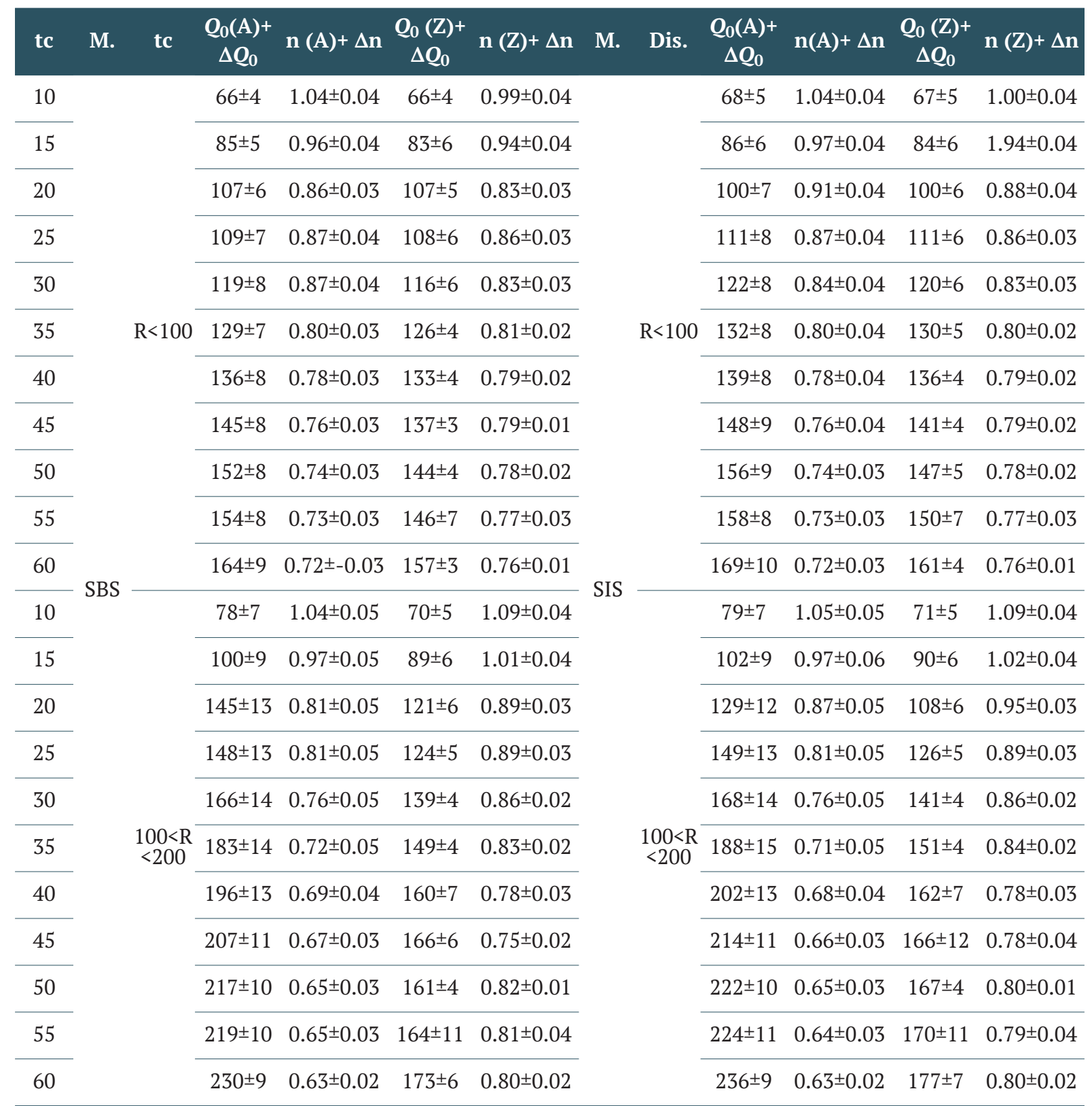

Note: $\Delta Q_{0}$ is the standard deviation of $Q_{0} ; \Delta n$ is the standard deviation of the frequency-dependent parameter; $\mathrm{A}$ and $\mathrm{Z}$ in parentheses show Alborz and NW Zagros regions respectively.

Table 4. Seismic robustness $Q_{0}$, frequency parameter $n$, and the attenuation factor for different lengths of the coda window W in Alborz and NW Zagros regions (Z Component). Abbreviations are: A: Alborz; Z: NW Zagros.

this difference increases along with the coda window length. The increase rate of $Q_{0}$ with the coda window length is not uniform in the second dataset. An interesting point is a great change in the increasing trend of $Q_{0}$ in $\mathrm{NW}$ Zagros compared to Alborz at $50 \mathrm{~s}$. Thus, the slope of $Q_{0}$ for Zagros decreases continually for the coda window length greater than $50 \mathrm{~s}$ until the last coda window, $60 \mathrm{~s}$. This decrease is stronger for NW Zagros compared to Alborz for the dataset-2. This means that the lower lithosphere beneath NW Zagros is more attenuative in comparison with the lower lithosphere beneath Alborz, whereas at shallower depths, there is no significant difference between their attenuation characteristics (Figure 5). As mentioned earlier, the coda waves at a given lapse time are generated by the first order scatters that are located on the surface of an ellipsoid with the earthquake source and the station as foci. The dimension of these ellipsoids depends on the coda window length and epicentral distance. For $\mathrm{R}<100 \mathrm{~km}$, the dimension of ellipsoids or penetration depths are lower than those for $100<\mathrm{R}<200 \mathrm{~km}$. 
Variation of coda wave attenuation in the Alborz and NW Zagros regions

\begin{tabular}{|c|c|c|c|c|c|c|c|c|c|c|c|c|}
\hline tc & M. & tc & $\begin{array}{c}Q_{0}(A)+ \\
\Delta Q_{0}\end{array}$ & $\mathbf{n}(\mathrm{A})+\Delta \mathbf{n}$ & $\begin{array}{c}Q_{0}(Z)+ \\
\Delta Q_{0}\end{array}$ & $\mathbf{n}(\mathbf{Z})+\Delta \mathbf{n}$ & M. & Dis. & $\begin{array}{c}Q_{0}(\mathrm{~A})+ \\
\Delta Q_{0}\end{array}$ & $\mathbf{n}(\mathbf{A})+\Delta \mathbf{n}$ & $\begin{array}{c}Q_{0}(Z)+ \\
\Delta Q_{0}\end{array}$ & $\mathbf{n}(\mathbf{Z})+\Delta \mathbf{n}$ \\
\hline 10 & \multirow{22}{*}{\multicolumn{2}{|c|}{$\mathrm{R}<100$}} & $66 \pm 4$ & $1.04 \pm 0.04$ & $66 \pm 4$ & $0.99 \pm 0.04$ & \multirow{22}{*}{\multicolumn{2}{|c|}{$\mathrm{R}<100$}} & $68 \pm 5$ & $1.04 \pm 0.04$ & $67 \pm 5$ & $1.00 \pm 0.04$ \\
\hline 15 & & & $85 \pm 5$ & $0.96 \pm 0.04$ & $83 \pm 6$ & $0.94 \pm 0.04$ & & & $86 \pm 6$ & $0.97 \pm 0.04$ & $84 \pm 6$ & $1.94 \pm 0.04$ \\
\hline 20 & & & $107 \pm 6$ & $0.86 \pm 0.03$ & $107 \pm 5$ & $0.83 \pm 0.03$ & & & $100 \pm 7$ & $0.91 \pm 0.04$ & $100 \pm 6$ & $0.88 \pm 0.04$ \\
\hline 25 & & & $109 \pm 7$ & $0.87 \pm 0.04$ & $108 \pm 6$ & $0.86 \pm 0.03$ & & & $111 \pm 8$ & $0.87 \pm 0.04$ & $111 \pm 6$ & $0.86 \pm 0.03$ \\
\hline 30 & & & $119 \pm 8$ & $0.87 \pm 0.04$ & $116 \pm 6$ & $0.83 \pm 0.03$ & & & $122 \pm 8$ & $0.84 \pm 0.04$ & $120 \pm 6$ & $0.83 \pm 0.03$ \\
\hline 35 & & & $129 \pm 7$ & $0.80 \pm 0.03$ & $126 \pm 4$ & $0.81 \pm 0.02$ & & & $132 \pm 8$ & $0.80 \pm 0.04$ & $130 \pm 5$ & $0.80 \pm 0.02$ \\
\hline 40 & & & $136 \pm 8$ & $0.78 \pm 0.03$ & $133 \pm 4$ & $0.79 \pm 0.02$ & & & $139 \pm 8$ & $0.78 \pm 0.04$ & $136 \pm 4$ & $0.79 \pm 0.02$ \\
\hline 45 & & & $145 \pm 8$ & $0.76 \pm 0.03$ & $137 \pm 3$ & $0.79 \pm 0.01$ & & & $148 \pm 9$ & $0.76 \pm 0.04$ & $141 \pm 4$ & $0.79 \pm 0.02$ \\
\hline 50 & & & $152 \pm 8$ & $0.74 \pm 0.03$ & $144 \pm 4$ & $0.78 \pm 0.02$ & & & $156 \pm 9$ & $0.74 \pm 0.03$ & $147 \pm 5$ & $0.78 \pm 0.02$ \\
\hline 55 & & & $154 \pm 8$ & $0.73 \pm 0.03$ & $146 \pm 7$ & $0.77 \pm 0.03$ & & & $158 \pm 8$ & $0.73 \pm 0.03$ & $150 \pm 7$ & $0.77 \pm 0.03$ \\
\hline 60 & & & $164 \pm 9$ & $0.72 \pm-0.03$ & $157 \pm 3$ & $0.76 \pm 0.01$ & & & $169 \pm 10$ & $0.72 \pm 0.03$ & $161 \pm 4$ & $0.76 \pm 0.01$ \\
\hline 10 & & & $78 \pm 7$ & $1.04 \pm 0.05$ & $70 \pm 5$ & $1.09 \pm 0.04$ & & & $79 \pm 7$ & $1.05 \pm 0.05$ & $71 \pm 5$ & $1.09 \pm 0.04$ \\
\hline 15 & & & $100 \pm 9$ & $0.97 \pm 0.05$ & $89 \pm 6$ & $1.01 \pm 0.04$ & & & $102 \pm 9$ & $0.97 \pm 0.06$ & $90 \pm 6$ & $1.02 \pm 0.04$ \\
\hline 20 & & & $145 \pm 13$ & $0.81 \pm 0.05$ & $121 \pm 6$ & $0.89 \pm 0.03$ & & & $129 \pm 12$ & $0.87 \pm 0.05$ & $108 \pm 6$ & $0.95 \pm 0.03$ \\
\hline 25 & & & $148 \pm 13$ & $0.81 \pm 0.05$ & $124 \pm 5$ & $0.89 \pm 0.03$ & & & $149 \pm 13$ & $0.81 \pm 0.05$ & $126 \pm 5$ & $0.89 \pm 0.03$ \\
\hline 30 & & & $166 \pm 14$ & $0.76 \pm 0.05$ & $139 \pm 4$ & $0.86 \pm 0.02$ & & & $168 \pm 14$ & $0.76 \pm 0.05$ & $141 \pm 4$ & $0.86 \pm 0.02$ \\
\hline 35 & & & $183 \pm 14$ & $0.72 \pm 0.05$ & $149 \pm 4$ & $0.83 \pm 0.02$ & & & $188 \pm 15$ & $0.71 \pm 0.05$ & $151 \pm 4$ & $0.84 \pm 0.02$ \\
\hline 40 & & & $196 \pm 13$ & $0.69 \pm 0.04$ & $160 \pm 7$ & $0.78 \pm 0.03$ & & & $202 \pm 13$ & $0.68 \pm 0.04$ & $162 \pm 7$ & $0.78 \pm 0.03$ \\
\hline 45 & & & $207 \pm 11$ & $0.67 \pm 0.03$ & $166 \pm 6$ & $0.75 \pm 0.02$ & & & $214 \pm 11$ & $0.66 \pm 0.03$ & $166 \pm 12$ & $0.78 \pm 0.04$ \\
\hline 50 & & & $217 \pm 10$ & $0.65 \pm 0.03$ & $161 \pm 4$ & $0.82 \pm 0.01$ & & & $222 \pm 10$ & $0.65 \pm 0.03$ & $167 \pm 4$ & $0.80 \pm 0.01$ \\
\hline 55 & & & $219 \pm 10$ & $0.65 \pm 0.03$ & $164 \pm 11$ & $0.81 \pm 0.04$ & & & $224 \pm 11$ & $0.64 \pm 0.03$ & $170 \pm 11$ & $0.79 \pm 0.04$ \\
\hline 60 & & & $230 \pm 9$ & $0.63 \pm 0.02$ & $173 \pm 6$ & $0.80 \pm 0.02$ & & & $236 \pm 9$ & $0.63 \pm 0.02$ & $177 \pm 7$ & $0.80 \pm 0.02$ \\
\hline
\end{tabular}

Note: $\Delta Q_{0}$ is the standard deviation of $Q_{0} ; \Delta n$ is the standard deviation of the frequency-dependent parameter; $\mathrm{A}$ and $\mathrm{Z}$ in parentheses show Alborz and NW Zagros regions respectively.

Table 5. Seismic robustness $Q_{0}$, frequency parameter $\mathrm{n}$, and the attenuation factor for different lengths of the coda window W in Alborz and NW Zagros regions (E-W Component). Abbreviations are: A: Alborz; Z: NW Zagros.

At $\mathrm{R}<100 \mathrm{~km}$, mainly the upper part of the lithosphere, which is no significant difference in parameters effects on $Q$ value in two regions, are scanned. So, a different pattern is not observed on $Q_{0}$ versus coda-window-length diagrams at the short distance. But for $100<\mathrm{R}<200 \mathrm{Km}$, the lower part of the lithosphere is scanned which has a significant difference in seismic attenuation characteristics due to the decoupling of Phanerozoic sedimentary phenomena in the basement of Zagros. Therefore a different pattern is observed on $\underline{Q}_{0}$ versus coda-window-length diagrams at the long distance.

Low $Q_{c}$ values characterize high tectonic activity and heterogeneity [Sertçelik, 2011]. Generally, the low value of $Q_{0}(<200)$ and high frequency parameter $(n)(>0.7)$ is related to the more seismic activity and heterogeneities in the upper part of the lithosphere [Aki, 2003]. Figures 5 and 6 show that, $Q_{0}$ and $n$ values strongly depend on the coda window length. For example, the $Q_{0}$ values obtained from the $\mathrm{Z}$ component and the SBS method vary from 66 at 


\begin{tabular}{|c|c|c|c|c|c|c|c|c|c|c|c|c|}
\hline tc & M. & tc & $\begin{array}{c}Q_{0}(\mathrm{~A})+ \\
\Delta Q_{0}\end{array}$ & $\mathbf{n}(\mathbf{A})+\Delta \mathbf{n}$ & $\begin{array}{c}Q_{0}(Z)+ \\
\Delta Q_{0}\end{array}$ & $\mathbf{n}(\mathbf{Z})+\Delta \mathbf{n}$ & M. & Dis. & $\begin{array}{c}\boldsymbol{Q}_{0}(\mathrm{~A})+ \\
\Delta Q_{0}\end{array}$ & $\mathbf{n}(\mathbf{A})+\Delta \mathbf{n}$ & $\begin{array}{c}Q_{0}(Z)+ \\
\Delta Q_{0}\end{array}$ & $\mathbf{n}(\mathbf{Z})+\Delta \mathbf{n}$ \\
\hline 10 & \multirow{22}{*}{ SBS } & \multirow{11}{*}{$\mathrm{R}<100$} & $68 \pm 4$ & $1.03 \pm 0.04$ & $66 \pm 4$ & $1.00 \pm 0.04$ & & \multirow{11}{*}{$\mathrm{R}<100$} & $68 \pm 5$ & $1.04 \pm 0.04$ & $66 \pm 4$ & $1.01 \pm 0.04$ \\
\hline 15 & & & $84 \pm 5$ & $0.96 \pm 0.04$ & $76 \pm 4$ & $0.98 \pm 0.03$ & & & $86 \pm 6$ & $0.96 \pm 0.04$ & $77 \pm 4$ & $0.98 \pm 0.03$ \\
\hline 20 & & & $105 \pm 5$ & $0.87 \pm 0.03$ & $99 \pm 7$ & $0.89 \pm 0.04$ & & & $98 \pm 6$ & $0.92 \pm 0.04$ & $92 \pm 7$ & $0.94 \pm 0.04$ \\
\hline 25 & & & $109 \pm 6$ & $0.87 \pm 0.03$ & $101 \pm 8$ & $0.91 \pm 0.05$ & & & $111 \pm 6$ & $0.87 \pm 0.03$ & $104 \pm 8$ & $0.91 \pm 0.05$ \\
\hline 30 & & & $117 \pm 6$ & $0.84 \pm 0.03$ & $111 \pm 7$ & $0.88 \pm 0.04$ & & & $119 \pm 7$ & $0.85 \pm 0.03$ & $114 \pm 5$ & $0.89 \pm 0.04$ \\
\hline 35 & & & $125 \pm 6$ & $0.82 \pm 0.03$ & $118 \pm 7$ & $0.87 \pm 0.04$ & & & $128 \pm 6$ & $0.81 \pm 0.03$ & $121 \pm 8$ & $0.87 \pm 0.04$ \\
\hline 40 & & & $132 \pm 6$ & $0.80 \pm 0.03$ & $127 \pm 7$ & $0.85 \pm 0.03$ & & & $136 \pm 6$ & $0.79 \pm 0.03$ & $130 \pm 8$ & $0.84 \pm 0.04$ \\
\hline 45 & & & $141 \pm 6$ & $0.77 \pm 0.03$ & $136 \pm 6$ & $0.83 \pm 0.03$ & & & $144 \pm 7$ & $0.77 \pm 0.03$ & $138 \pm 7$ & $0.83 \pm 0.03$ \\
\hline 50 & & & $149 \pm 6$ & $0.75 \pm 0.02$ & $143 \pm 6$ & $0.81 \pm 0.02$ & & & $152 \pm 6$ & $0.75 \pm 0.02$ & $147 \pm 7$ & $0.81 \pm 0.03$ \\
\hline 55 & & & $154 \pm 7$ & $0.73 \pm 0.03$ & $145 \pm 7$ & $0.80 \pm 0.03$ & & & $157 \pm 7$ & $0.73 \pm 0.03$ & $150 \pm 8$ & $0.78 \pm 0.03$ \\
\hline 60 & & & $164 \pm 7$ & $0.72 \pm-0.03$ & $152 \pm 4$ & $0.80 \pm 0.02$ & & & $167 \pm 7$ & $0.72 \pm 0.03$ & $157 \pm 4$ & $0.79 \pm 0.02$ \\
\hline 10 & & \multirow{11}{*}{$\begin{array}{c}100<\mathrm{R} \\
<200\end{array}$} & $77 \pm 6$ & $1.04 \pm 0.05$ & $72 \pm 4$ & $1.08 \pm 0.03$ & & \multirow{11}{*}{$\begin{array}{c}100<\mathrm{R} \\
<200\end{array}$} & $78 \pm 6$ & $1.04 \pm 0.05$ & $72 \pm 4$ & $1.08 \pm 0.03$ \\
\hline 15 & & & $101 \pm 9$ & $0.96 \pm 0.06$ & $89 \pm 4$ & $1.02 \pm 0.03$ & & & $104 \pm 9$ & $0.96 \pm 0.05$ & $89 \pm 5$ & $1.02 \pm 0.03$ \\
\hline 20 & & & $136 \pm 11$ & $0.84 \pm 0.05$ & $119 \pm 3$ & $0.91 \pm 0.01$ & & & $122 \pm 10$ & $0.90 \pm 0.05$ & $111 \pm 6$ & $0.93 \pm 0.03$ \\
\hline 25 & & & $139 \pm 11$ & $0.84 \pm 0.05$ & $122 \pm 4$ & $0.92 \pm 0.02$ & & & $142 \pm 11$ & $0.84 \pm 0.05$ & $124 \pm 4$ & $0.92 \pm 0.02$ \\
\hline 30 & & & $157 \pm 10$ & $0.78 \pm 0.04$ & $131 \pm 2$ & $0.90 \pm 0.01$ & & & $161 \pm 11$ & $0.78 \pm 0.04$ & $133 \pm 3$ & $0.90 \pm 0.01$ \\
\hline 35 & & & $175 \pm 10$ & $0.74 \pm 0.03$ & $140 \pm 3$ & $0.88 \pm 0.01$ & & & $177 \pm 10$ & $0.73 \pm 0.03$ & $143 \pm 3$ & $0.88 \pm 0.01$ \\
\hline 40 & & & $188 \pm 9$ & $0.71 \pm .03$ & $147 \pm 5$ & $0.87 \pm 0.02$ & & & $190 \pm 10$ & $0.71 \pm 0.03$ & $150 \pm 5$ & $0.87 \pm 0.02$ \\
\hline 45 & & & $198 \pm 10$ & $0.68 \pm 0.03$ & $157 \pm 4$ & $0.84 \pm 0.02$ & & & $202 \pm 11$ & $0.68 \pm 0.03$ & $159 \pm 4$ & $0.84 \pm 0.02$ \\
\hline 50 & & & $206 \pm 8$ & $0.68 \pm 0.02$ & $159 \pm 7$ & $0.83 \pm 0.02$ & & & $209 \pm 9$ & $0.68 \pm 0.03$ & $163 \pm 7$ & $0.84 \pm 0.02$ \\
\hline 55 & & & $214 \pm 10$ & $0.65 \pm 0.03$ & $161 \pm 12$ & $0.82 \pm 0.04$ & & & $218 \pm 11$ & $0.65 \pm 0.03$ & $164 \pm 12$ & $0.81 \pm 0.04$ \\
\hline 60 & & & $222 \pm 8$ & $0.65 \pm 0.02$ & $173 \pm 10$ & $0.78 \pm 0.04$ & & & $228 \pm 10$ & $0.64 \pm 0.02$ & $177 \pm 11$ & $0.78 \pm 0.04$ \\
\hline
\end{tabular}

Table 6. Seismic robustness $Q_{0}$, frequency parameter $n$, and the attenuation factor for different lengths of the coda window W in Alborz and NW Zagros regions (N-S Component). Abbreviations are: A: Alborz; Z: NW Zagros.

$\mathrm{W}=10 \mathrm{~s}$ to 164 at $\mathrm{W}=60 \mathrm{~s}$, and the frequency-dependent $(n)$ varies from 1.04 to 0.72 for the dataset- 1 in Alborz region, depending on the coda window length (See Tables 4-6 for full details). Therefore, these results illustrate that the Alborz and NW Zagros regions are tectonically active regions.

An approximate estimation of the maximum depth through the coda window length and the average epicentral distance can be obtained using the Pulli [1984] method based on the single backscattering model proposed by Aki [1969] and Aki and Chouet [1975]. In this model, the estimated attenuation of coda wave is the average decay of amplitudes of backscattered waves on the surface of an ellipsoid volume with the earthquake source and the station as foci [Pulli 1984; Gupta et al., 1998; Rahimi et al., 2010]. In other words, the coda waves at a given lapse time are generated by the first order scatters that are located on the surface of an ellipsoid [Malin, 1978]. The semi-major and semi-minor axes of the surface projected ellipsoid are given by $a=V_{s} t / 2$ and $b=\left(a^{2}-\left(\Delta^{2} / 4\right)\right)^{1 / 2}$ respectively, where $\mathrm{V}_{\mathrm{S}}$ is $\mathrm{S}$ wave velocity, $\Delta$ is average epicentral distance and $\mathrm{t}$ is the average lapse time [Pulli, 1984]. The maximum depth of volume of ellipsoid from which coda wave generation would occur for different lapse times which is given 

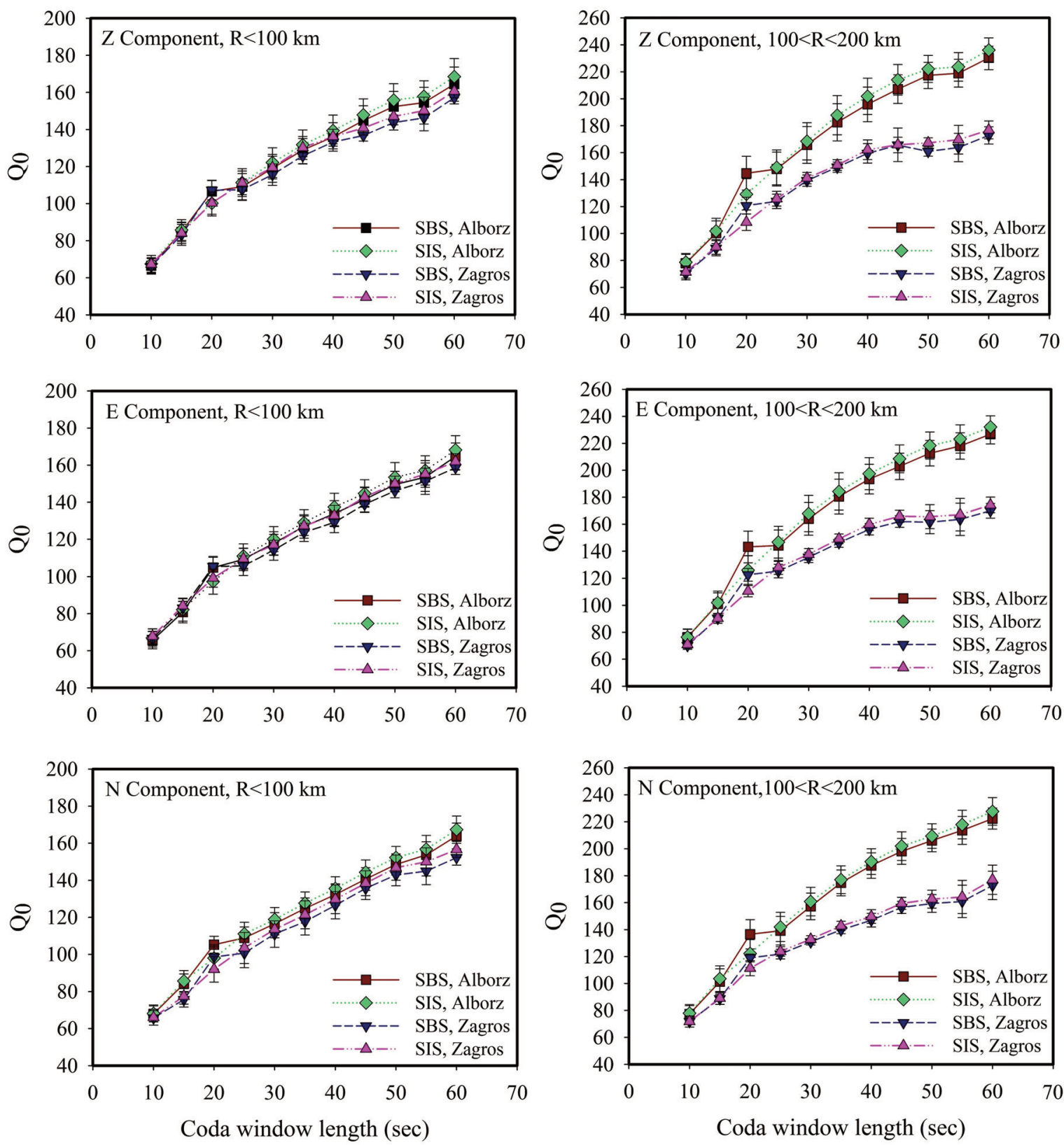

Figure 5. The variation of $Q_{0}$ versus coda window length (sec.) for two regions for epicentral distance ranges (left) $\mathrm{R}<100$ $\mathrm{km}$ and (right) $100<\mathrm{R}<200 \mathrm{~km}$ for all three components.

by $\mathrm{h}=\mathrm{b}+\mathrm{h}_{\mathrm{av}}$, where $\mathrm{h}_{\mathrm{av}}$ is the average focal depth $(\sim 10 \mathrm{~km})$ of events [Pulli, 1984; Havskov et al., 1989; Canas et al., 1995; Rahimi et al., 2010; Sertçelik, 2011]. We have assumed an S-wave velocity of $3.5 \mathrm{~km} / \mathrm{s}$ based on the previous studies [Rahimi et al., 2010; Motaghi et al., 2014; Irandoust et al., 2015; Rastgoo et al., 2018]. The average lapse time is taken to be $t=t_{\text {start }}+\mathrm{W} / 2$, where $t_{\text {start }}$ is the starting time of the coda window and $\mathrm{W}$ is the coda window length. The observed $Q_{c}$ reflects the average attenuation properties of the volume of the ellipsoid.

The analysis of two data sets at different coda window lengths allows us to estimate the coda quality factor at different depths in the study area. As mentioned above, in order to calculate the maximum depth of scatters responsible for the generation of coda waves, for each coda window length and in each dataset it is required to have $\Delta$ and $t_{\text {start }}$ related to the two datasets including rays with epicentral distances $R<100 \mathrm{~km}$ and $100<R<200 \mathrm{~km}$ in both study areas. The attenuation variation with depth in the two datasets is shown in Figure 7 . The values of $\Delta$ and $t_{\text {start }}$ in the first dataset in Alborz are, respectively, $63 \mathrm{~km}$ and $39.4 \mathrm{~s}$ and in NW Zagros $72 \mathrm{~km}$ and $44.8 \mathrm{~s}$. The values in 

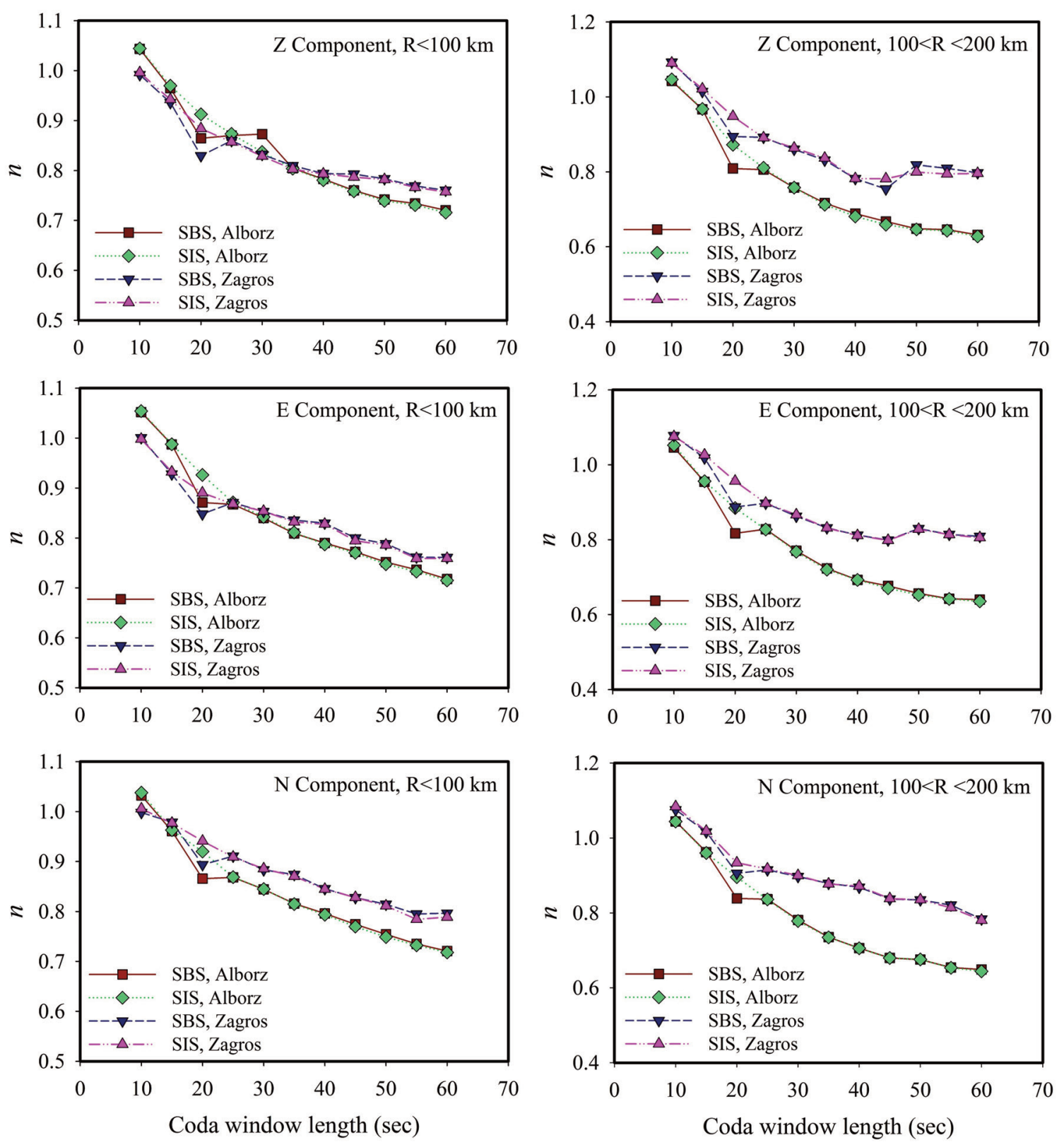

Figure 6. Plot of average values of $n$ versus coda window length at different central frequencies for two regions for epicentral distance ranges; (left) $\mathrm{R}<100 \mathrm{~km}$ and (right) $100<\mathrm{R}<200 \mathrm{~km}$ for all three components.

the second data set are $143 \mathrm{~km}$ and $83.4 \mathrm{~s}$ in Alborz and $147 \mathrm{~km}$ and $85.4 \mathrm{~s}$ in NW Zagros. The penetration depths and coverage of the area for estimated $Q_{c}$ for different groups of data are given in Table 7 .

The existence of a change in the curve for Alborz in the first dataset can be interpreted as a change in the attenuation structure from depth $\sim 110 \mathrm{~km}$ to $\sim 125 \mathrm{~km}$ (Figure 7a). This figure shows that the trend of the attenuation curve for the Alborz and NW Zagros regions is similar and decreases by increasing depth, as $Q_{0}$ has a steep slope versus depth. This observation implies the existence of a high attenuation (low velocity) anomalous structure beneath the lithosphere of Alborz. Reported lithospheric mantle heterogeneities beneath the Iranian Plateau [Tunini et al., 2015], shows that the Lithosphere-Asthenosphere Boundary (LAB) shallows to 120 km beneath Alborz.

The attenuation variation with depth in the second dataset including the epicentral distance $100<R<200 \mathrm{~km}$ has been shown in Figure $7 \mathrm{~b}$. This dataset shows the average $Q_{0}$ over a maximum depth of $145 \mathrm{~km}$. The $Q_{0}$ curve in this figure shows that the trend of attenuation in the Alborz and NW Zagros regions is similar and decreases as the 
Variation of coda wave attenuation in the Alborz and NW Zagros regions

\begin{tabular}{|c|c|c|c|c|c|c|}
\hline $\begin{array}{c}\text { Coda } \\
\text { window }\end{array}$ & \multicolumn{2}{|c|}{$\boldsymbol{Q}_{c}$} & \multicolumn{2}{|c|}{ Penetration depth (km) } & \multicolumn{2}{|c|}{ Coverage of Area $\left(\mathrm{km}^{2}\right)$} \\
\hline & Dataset-1 & Dataset-2 & Dataset-1 & Dataset-2 & Dataset-1 & Dataset-2 \\
\hline \multicolumn{7}{|c|}{ Alborz } \\
\hline 10 & $(66 \pm 4) f^{(1.04 \pm 0.04)}$ & $(78 \pm 7) f^{(1.04 \pm 0.05)}$ & 82 & 149 & 17,789 & 68,315 \\
\hline 15 & $(85 \pm 5) f^{(0.96 \pm 0.04)}$ & $(100 \pm 9) f^{(0.97 \pm 0.05)}$ & 87 & 152 & 19,892 & 71,059 \\
\hline 20 & $(107 \pm 6) f^{(0.86 \pm 0.03)}$ & $(145 \pm 13) f^{(0.81 \pm 0.05)}$ & 91 & 158 & 22,052 & 76,783 \\
\hline 25 & $(109 \pm 7) f^{(0.87 \pm 0.04)}$ & $(148 \pm 13) f^{(0.81 \pm 0.05)}$ & 95 & 163 & 24,084 & 80,951 \\
\hline 30 & $(119 \pm 8) f^{(0.87 \pm 0.04)}$ & $(166 \pm 14) f^{(0.76 \pm 0.05)}$ & 99 & 167 & 26,596 & 84,767 \\
\hline 35 & $(129 \pm 7) f^{(0.80 \pm 0.03)}$ & $(183 \pm 14) f^{(0.72 \pm 0.05)}$ & 104 & 171 & 29,321 & 89,374 \\
\hline 40 & $(136 \pm 8) f^{(0.78 \pm 0.03)}$ & $(196 \pm 13) f^{(0.69 \pm 0.04)}$ & 109 & 176 & 32,270 & 94,340 \\
\hline 45 & $(145 \pm 8) f^{(0.76 \pm 0.03)}$ & $(207 \pm 11) f^{(0.67 \pm 0.03)}$ & 113 & 181 & 35,085 & 99,459 \\
\hline 50 & $(152 \pm 8) f^{(0.74 \pm 0.03)}$ & $(217 \pm 10) f^{(0.65 \pm 0.03)}$ & 118 & 185 & 37,999 & 103,645 \\
\hline 55 & $(154 \pm 8) f^{(0.73 \pm 0.03)}$ & $(219 \pm 10) f^{(0.65 \pm 0.03)}$ & 123 & 190 & 41,432 & 109,463 \\
\hline 60 & $(164 \pm 9) f^{(0.72 \pm-0.03)}$ & $(230 \pm 9) f^{(0.63 \pm 0.02)}$ & 127 & 195 & 44,535 & 115,438 \\
\hline \multicolumn{7}{|c|}{ NW Zagros } \\
\hline 10 & $(66 \pm 4) f^{(0.99 \pm 0.04)}$ & $(70 \pm 5) f^{(1.09 \pm 0.04)}$ & 91 & 150 & 22,511 & 70,005 \\
\hline 15 & $(83 \pm 6) f^{(0.94 \pm 0.04)}$ & $(89 \pm 6) f^{(1.01 \pm 0.04)}$ & 95 & 156 & 24,498 & 74,685 \\
\hline 20 & $(107 \pm 5) f^{(0.83 \pm 0.03)}$ & $(121 \pm 6) f^{(0.89 \pm 0.03)}$ & 99 & 161 & 26,801 & 79,348 \\
\hline 25 & $(108 \pm 6) f^{(0.86 \pm 0.03)}$ & $(124 \pm 5) f^{(0.89 \pm 0.03)}$ & 103 & 165 & 29,259 & 83,069 \\
\hline 30 & $(116 \pm 6) f^{(0.83 \pm 0.03)}$ & $(139 \pm 4) f^{(0.86 \pm 0.02)}$ & 107 & 170 & 31,633 & 88,010 \\
\hline 35 & $(126 \pm 4) f^{(0.81 \pm 0.02)}$ & $(149 \pm 4) f^{(0.83 \pm 0.02)}$ & 112 & 175 & 34,743 & 93,547 \\
\hline 40 & $(133 \pm 4) f^{(0.79 \pm 0.02)}$ & $(160 \pm 7) f^{(0.78 \pm 0.03)}$ & 117 & 179 & 38,172 & 97,497 \\
\hline 45 & $(137 \pm 3) f^{(0.79 \pm 0.01)}$ & $(166 \pm 6) f^{(0.75 \pm 0.02)}$ & 122 & 183 & 41,324 & 101,952 \\
\hline 50 & $(144 \pm 4) f^{(0.78 \pm 0.02)}$ & $(161 \pm 4) f^{(0.82 \pm 0.01)}$ & 127 & 188 & 44,666 & 107,783 \\
\hline 55 & $(146 \pm 7) f^{(0.77 \pm 0.03)}$ & $(164 \pm 11) f^{(0.81 \pm 0.04)}$ & 131 & 193 & 48,238 & 113,650 \\
\hline 60 & $(157 \pm 3) f^{(0.76 \pm 0.01)}$ & $(173 \pm 6) f^{(0.80 \pm 0.02)}$ & 136 & 197 & 52,181 & 118,284 \\
\hline
\end{tabular}

The area coverage is computed using the formulation given by Pulli [1984]

Table 7. Penetration depth and coverage of the area for estimated $Q_{c}$ functions obtained from vertical component of local earthquakes with SBS method in Alborz and NW Zagros.

depth increases to $180 \mathrm{~km}$. Beneath $\sim 180 \mathrm{~km}$, the trend of $Q_{0}$ value for NW Zagros changes and the attenuation increases by increasing depth, so that in this part of the mantle, NW Zagros gets more attenuation, as it decreases less rapidly compared to lithosphere of the Alborz region. This could also indicate the presence of a transparent mantle beneath $\sim 180 \mathrm{~km}$ in the study area. The existence of a LAB at $210 \mathrm{~km}$ depth beneath Zagros has been reported by Tunini et al. [2015]. 


\section{Reza Emami et al.}
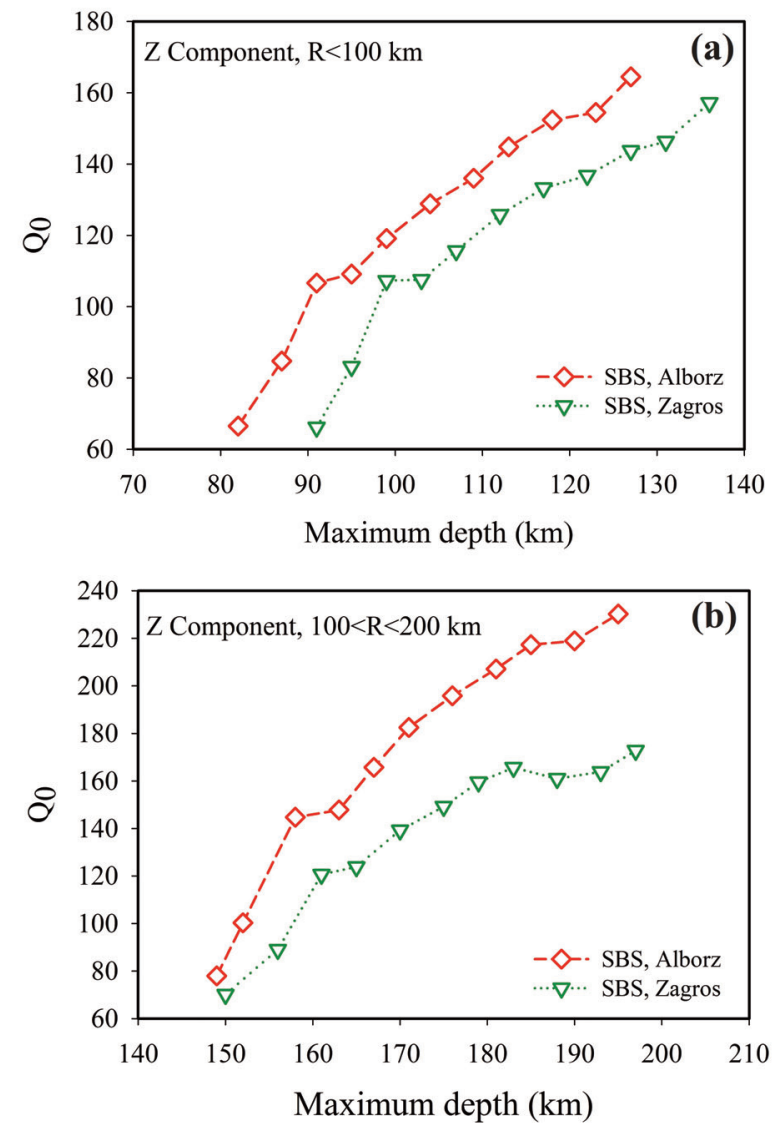

Figure 7. The variation of $Q_{0}$ versus maximum depth $(\mathrm{km})$ for two regions for epicentral distance ranges; a) $\mathrm{R}<100 \mathrm{~km}$ and, b) $100<\mathrm{R}<200 \mathrm{~km}$ for the vertical component.

\subsection{Discussion}

In this study, coda- $Q$ values have been estimated for the Alborz and NW Zagros regions from the vertical and horizontal components using the SBS [Aki and Choet, 1975] and SIS [Sato, 1977] methods by equations (3) and (4), respectively. The results show that the estimated quality factor using the SIS method is slightly higher than to that value of the SBS method. The only difference between these equations is the Geometrical-Spreading Correction (GSC) factor of coda wave amplitudes, which are $t$ and $r / \sqrt{k}(a)$ for the SBS and SIS methods, respectively. Therefore, the estimated $Q_{c}$ value only depends on the calculated GSC values by the SBS and SIS methods. The coda- $Q$ values are proportional to the slope of geometrical correction. When comparing the normalized amplitude (NA) of geometrical correction it was shown that the NA values of the SIS method have slightly higher slopes compared with the SBS method, which gives higher values for estimated $Q_{c}$ at short lapse times, $t_{c}$, less than $85 \mathrm{~s}$ [Farrokhi et al., 2015].

Due to the scattering nature of the coda waves, they come from all directions [Hovskov et al., 2016). Therefore, we would not expect any difference between the components [Del Pezzo et al., 1985; Sato et al., 2012]; hence, all the three components can be used. Furthermore, in order to have a large number of observations, all three components should be used [Hovskov et al., 2016]. The estimated results using the vertical and horizontal components are tabulated in Tables 4 to 6.

In this study, the relationship between the obtained quality factors for the two regions and the abovementioned properties were investigated.

As discussed earlier, for $\mathrm{R}<100 \mathrm{~km}$ the coda waves attenuation in Zagros is slightly higher than in Alborz, but it isn't significant and are pretty similar (Figure 5). Our results are in good agreement with those obtained in previous studies [Ghasemi et al., 2009; Sedaghati and Pezeshk, 2016b; Darzi et al., 2019] which used the Analysis of Variance 


\section{Variation of coda wave attenuation in the Alborz and NW Zagros regions}

(ANOVA) technique. They concluded that there is no significant difference between the patterns of the attenuation PGAs (Peak Grand Accelerations) and SAs (Spectral Acceleration) with distance for the Zagros and Alborz regions.

The coda lapse time is related to the region of coda wave sampling. Longer lapse times represent longer travelled distances and larger depth intervals [Sertçelik, 2011; Irandoust et al., 2015]. Recent studies [e.g., Shapiro et al., 2000] have revealed that at short distances the scattering attenuation is dominant while at larger distances the intrinsic absorption which is very sensitive to the temperature is dominant [Gao, 1992; Havskov et al., 2016]. Seismic attenuation is a complicated process, which can be caused or affected by earth properties such as seismicity, temperature, the thickness of sediments, rock types, and the age of the earth. It is noteworthy that, the strong effect of temperature on seismic attenuation has been calculated in a number of experimental studies, and it was used recently to correlate seismic attenuation anomalies in the mantle with temperature variations [e.g., Durak et al., 1993; Romanowicz, 1994; Mitchell, 1995; Romanowicz, 1995; Artemieva et al., 2004].

Due to the similarity of the average temperature of the two regions up to a depth of approximately $100 \mathrm{~km}$ (Tunini et al., 2015), the slightly higher attenuation at shallower depths in the Zagros region can be attributed to the extremely high seismicity and large sedimentary cover beneath Zagros compared to Alborz. Zagros shows the thickest sedimentary basin of Iran (Teknik and Ghods, 2017). Therefore, the stratigraphic thickness reaches to a maximum of $14 \mathrm{~km}$ in the NW of Zagros [Molinaro et al., 2005; Casciello et al., 2009; Nissan et al., 2011]. While the stratigraphic thickness of sediments deposited from the Precambrian to the early Cenozoic reaches to a maximum of $10 \mathrm{~km}$ in Alborz [Assereto, 1966]. The volcano-clastic sedimentary column is exposed mostly in the southern hills of the Alborz Mountains with a maximum stratigraphic thickness of $6 \mathrm{~km}$ [Teknik and Ghods, 2017].

If we want to compare the seismicity of the two regions, we can say that Zagros is more active. The Zagros belt is a weak lithosphere, incapable of sustaining high strain levels and a very heterogeneous stress system. Most earthquakes occur in such weak crusts, and their occurrence has often been attributed to the movements of small fault segments (Zamani and Agh-Atabai, 2011). It is the seismically most active region of Iran, such that more than $50 \%$ of the teleseismic recorded earthquakes in Iran have occurred in the Zagros region [Mirzaei et al., 1998; Zamani and Agh-Atabai, 2011]. Like Zagros though to a smaller degree, Alborz is a zone of high seismicity, and strong earthquakes have been recorded in the area. The strongest earthquake recorded is the Damghan earthquake of $\mathrm{M}_{\mathrm{S}}$ 7.9, which occurred on 22 Dec 856 and caused 200,000 fatalities [Ambraseys and Melville, 1982].

As Figure 5 shows, unlike $\mathrm{R}<100 \mathrm{~km}$, the difference of the obtained coda waves attenuation for both study areas increases and becomes much stronger while the length of coda window increases for the second dataset. This suggests that the lithosphere beneath NW Zagros is more attenuative compared to that below Alborz. The significant difference between $Q_{c}$ values in the two regions for $100<\mathrm{R}<200$ is interesting but this is explainable. According to the suggested model of Mohammadi et al., [2013], the remnant of the fossil Neo-Tethyan subduction exists beneath Zagros and SSZ in depth range of 100-150 km. The combination of our results with Mohammadi et al., [2013] emphasizes low velocity zone exists may be due to the partial melting of the remnant of the fossil Neo-Tethyan. The average temperature of the two regions are similar from the surface to a depth of $100 \mathrm{~km}$ [Tunini et al., 2015] but for much of the Phanerozoic, Zagros was a subsiding continental margin which was accumulating a thick package of sediments. Basins that were filled with sediments of low conductivity are able to retain high temperatures long after initial lithospheric stretching increases the geothermal gradient [McKenzie, 1981; Jackson, 1987], suggesting that the Arabian basement underlying the sediments of Zagros may remain hot and weak [Nissen et al., 2011]. The increased temperature of the basement of Zagros as a result of the decoupling of Phanerozoic sedimentary maybe have an important role in decreasing the quality factor of seismic waves.

\subsection{Comparison of $Q_{c}$ with other observations}

In this study, Coda- $Q$ values and its frequency-dependent relation were estimated for different coda window lengths using the equation $Q=Q_{0} f^{n}$ for Alborz and NW Zagros. The results showed that Alborz and NW Zagros regions are in tectonically active regions. In the last decade, some research has been undertaken to estimate the $Q_{c}$ frequency relations at different tectonic regions of Iran [e.g., Rahimi et al., 2010; Rahimi and Hamzehloo, 2008; Ma'hood and Hamzehloo, 2009; Farrokhi et al., 2015; Irandoust et al., 2015 and Rahimi et al., 2009]. Rahimi et al. [2010] have evaluated a relation $Q_{c}=79 f^{1.07}$ with a coda window length of $25 \mathrm{~s}$, in the central Alborz region which is the central part of our study area. The dataset used in Rahimi et al. [2010] consisted of 345 local earthquakes $(2<\mathrm{M}<5)$ 


\section{Reza Emami et al.}

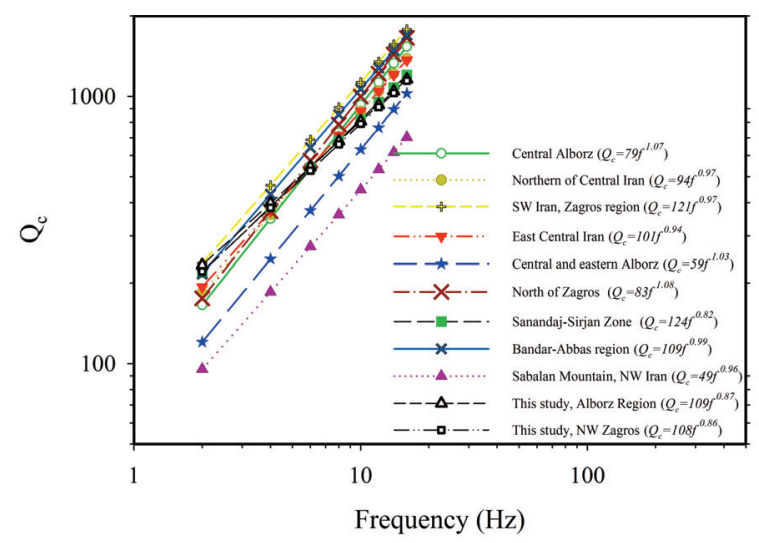

Figure 8. Comparison of frequency-dependent $Q_{c}$ values estimated for the Alborz and NW Zagros regions in our study with those reported from different regions of Iran: Central Alborz and Northern of Central Iran (Rahimi et al. 2010); Zagros region, SW Iran (Rahimi \& Hamzeloo, 2008); East Central Iran (Ma’hood\& Hamzehloo, 2009); Central and eastern Alborz (Farrokhi et al. 2015); North of Zagros, Sanandaj-Sirjan Zone (SSZ) and BandarAbbas region (Zagros-Makran transition zone) (Irandoust et al. 2015); SE Sabalan Mountain (Rahimi et al. 2009).

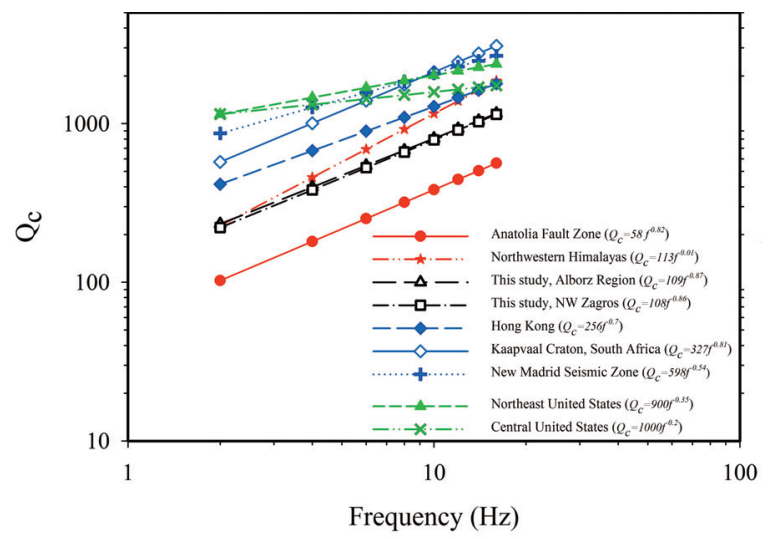

Figure 9. Comparison of coda- $Q$ values $\left(Q_{c}\right)$ of Alborz and NW Zagros with reported $Q_{c}$ values of other regions of the world: Anatolia Fault Zone (Sertçelik, 2012); Northwestern Himalayas (Mukhopadhyay et al. 2006); Hong Kong (Mak et al. 2004); Kaapvaal Craton, South Africa (Birch et al. 2015); New Madrid Seismic Zone (Sedaghati \& Pezeshk, 2016a); Northeast United States and Central United States (Singh \& Hermann, 1983).

with the epicentral distance less than $100 \mathrm{~km}$. We derived $Q_{c}=109 f^{0.87}$ at same coda window length in the Alborz region.

The values of $Q_{0}$ and the frequency-dependent parameter ( $n$ ) given by Rahimi et al. [2010] are smaller and greater respectively than those to our estimated values. The $Q_{0}$ values given by them are close to our estimated values for shorter coda window lengths.

Farrokhi et al [2015] estimated $Q_{c}=59 f^{1.03}$ with a coda window length of $30 \mathrm{~s}$ for horizontal components in the Central and eastern Alborz. The dataset used in Farrokhi et al. [2015], consisted of 746 local earthquakes with local magnitude $M_{L}$ from 1.1 to 5.7. In fact, their studied area is the central and eastern Alborz, as well as the northern part of central Iran, but our study area includes the whole Alborz Mountains.

The second region, NW Zagros, is a collision active zone in the west of Iran. An average $Q_{\mathrm{c}}=121 f^{0.97}$ frequency relation estimated by Rahimi and Hamzehloo [2008], for the vertical component at coda window lengths of 25s in the Zagros continental collision zone, Southwestern Iran; whereas, we derived $Q_{c}=108 f^{0.86}$ for the vertical component at same coda window length. The epicentral distances of local earthquakes range from 120 to $200 \mathrm{~km}$ 


\begin{tabular}{|c|c|c|c|c|c|c|c|}
\hline & No. & Seismicity & Region & Source & $Q_{0}$ & $n$ & W (s) \\
\hline \multirow{11}{*}{$\begin{array}{l}\text { Studies in } \\
\text { Iran }\end{array}$} & 1 & Active & Central Alborz & $\begin{array}{l}\text { Rahimi et al., } \\
\text { [2010] }\end{array}$ & 79 & 1.07 & 25 \\
\hline & 2 & Active & Northern of Central Iran & $\begin{array}{l}\text { Rahimi et al., } \\
{[2010]}\end{array}$ & 94 & 0.97 & 25 \\
\hline & 3 & Active & $\begin{array}{l}\text { SW Iran, } \\
\text { Zagros region }\end{array}$ & $\begin{array}{c}\text { Rahimi and } \\
\text { Hamzehloo, } 2008\end{array}$ & 121 & 0.97 & 25 \\
\hline & 4 & Active & East Central Iran & $\begin{array}{c}\text { Ma'hoodand } \\
\text { Hamzehloo, } 2009\end{array}$ & 101 & 0.94 & 30 \\
\hline & 5 & Active & $\begin{array}{l}\text { Central and eastern } \\
\text { Alborz, Iran }\end{array}$ & $\begin{array}{c}\text { Farrokhi et al., } \\
{[2015]}\end{array}$ & 59 & 1.03 & 30 \\
\hline & 6 & Active & $\begin{array}{l}\text { North of Zagros } \\
\text { (Lorestan Izeh) }\end{array}$ & $\begin{array}{l}\text { Irandoust et al., } \\
{[2015]}\end{array}$ & 83 & 1.08 & 30 \\
\hline & 7 & Active & $\begin{array}{c}\text { Sanandaj-Sirjan Zone } \\
\text { (SSZ) }\end{array}$ & $\begin{array}{l}\text { Irandoust et al., } \\
{[2015]}\end{array}$ & 124 & 0.82 & 30 \\
\hline & 8 & Active & Bandar-Abbas region & $\begin{array}{l}\text { Irandoust et al., } \\
{[2015]}\end{array}$ & 109 & 0.99 & 30 \\
\hline & 9 & Active & $\begin{array}{l}\text { SE Sabalan Mountain, } \\
\text { NW Iran }\end{array}$ & $\begin{array}{c}\text { Rahimi et al., } \\
\text { [2009] }\end{array}$ & 49 & 0.96 & - \\
\hline & 10 & Active & This study, Alborz region & - & 109 & 0.87 & 25 \\
\hline & 11 & Active & $\begin{array}{c}\text { This study, } \\
\text { NW Zagros region }\end{array}$ & - & 108 & 0.86 & 25 \\
\hline \multirow{9}{*}{$\begin{array}{l}\text { Studies in } \\
\text { the world }\end{array}$} & 1 & Active & $\begin{array}{l}\text { Anatolia Fault } \\
\text { Zone,Turkey }\end{array}$ & $\begin{array}{l}\text { Sertçelik, } \\
\text { [2012] }\end{array}$ & 58 & 0.82 & $20-30-40$ \\
\hline & 2 & Active & $\begin{array}{l}\text { Northwestern } \\
\text { Himalayas }\end{array}$ & $\begin{array}{c}\text { Mukhopadhyay et al., } \\
{[2006]}\end{array}$ & 113 & 1.01 & - \\
\hline & 3 & Active & Alborz Region & This study & 109 & 0.87 & 25 \\
\hline & 4 & Active & NW Zagros & This study & 108 & 0.86 & 25 \\
\hline & 5 & Moderate & Hong Kong & Mak et al., [2004] & 256 & 0.70 & - \\
\hline & 6 & Moderate & $\begin{array}{l}\text { KaapvaalCraton, } \\
\text { South Africa }\end{array}$ & Birch et al.,[2015] & 327 & 0.81 & - \\
\hline & 7 & Moderate & $\begin{array}{l}\text { New Madrid } \\
\text { Seismic Zone }\end{array}$ & $\begin{array}{c}\text { Sedaghatiand Pezeshk, } \\
\text { [2016a] }\end{array}$ & 598 & 0.54 & 40 \\
\hline & 8 & Stable & Northeast United States & $\begin{array}{c}\text { Singh and Hermann, } \\
{[1983]}\end{array}$ & 900 & 0.35 & - \\
\hline & 9 & Stable & Central United States & $\begin{array}{c}\text { Singh and Hermann, } \\
\text { [1983] }\end{array}$ & 1000 & 0.20 & - \\
\hline
\end{tabular}

Table 8. Parameters of the Selected Coda Quality Factor Functions for some of studies in Iran (upper part) and in the world (lower part).

for Rahimi and Hamzehloo (2008), whereas epicentral distances used in this study range from 4.5 to $100 \mathrm{~km}$.

According to the $Q_{c}$ frequency relation provided by Irandoust et al. [2015], $Q_{0}$ and $n$ are 109 and 0.99, respectively, in SE Zagros (the Bandar-Abbas region) at the coda window length of $30 \mathrm{~s}$. The epicentral distance of events $(2.5<\mathrm{M}<5)$ used in their study are less than $100 \mathrm{~km}$. In the present study, the obtained relation for $Q_{\mathrm{c}}$ for NW of Zagros is $Q_{c}=108 f^{0.86}$. It is obvious that the $Q_{0}$ and $n$ values given by them are similar and greater, respectively, to those results of our estimates. As mentioned earlier, the parameter $n$ is indicative of the degree of heterogeneity of the crust [Aki, 1981], therefore, it can be said that NW Zagros is more homogeneous in compared to SE Zagros.

Irandoust et al. [2015] also estimated $Q_{c}=83 f^{1.08}$ for north of Zagros, that have an overlap with our study area. The difference in the obtained results of the two studies can be due to the distinct part of the studies areas as well 


\section{Reza Emami et al.}

as different datasets. Table 8 (upper part) presents $Q_{0}$ and $n$ values and Figure 8 shows the comparison coda $Q$ variation with those of other studied in different regions of Iranian Plateau.

We have compared some of the results of $Q_{c}$ studies obtained by various researchers in the world [Sertçelik, 2012; Mukhopadhyay et al., 2006; Mak et al., 2004; Birch et al., 2015; Sedaghati and Pezeshk, 2016a; Singh and Hermann, 1983]. The obtained values are comparable to the $Q_{c}$ frequency trend of the Northwestern Himalayas $\left(Q_{c}=113 f^{1.01}\right)$; the East Anatolia Fault Zone, Turkey $\left(Q_{c}=58 f^{0.82}\right)$; the New Madrid Seismic Zone $\left(Q_{c}=598 f^{054}\right)$, Hong Kong $\left(Q_{c}=256 f^{0.7}\right)$; Kaapvaal craton, South Africa $\left(Q_{c}=327 f^{0.81}\right)$, Northeast United States $\left(Q_{c}=900 f^{0.35}\right)$, and Central United States $\left(Q_{c}=1000 f^{0.20}\right)$. Table 8 (lower part) compares the $Q$-factor function obtained in this study compared to those from the other regions in the world. As shown in Figure 9, the Alborz and NW Zagros regions obviously follow the trend for regions with active seismic activities.

\section{Conclusion}

The quality factor $\left(Q_{c}\right)$ and the frequency-dependent parameter $(n)$, in the lithosphere of the Alborz and NW Zagros regions, were estimated from an analysis of the coda waves of 677 local events which were recorded by short period and broadband seismic stations of IRSC and IIEES. In this study, the vertical and horizontal components of seismograms have been analysed to study the lateral and depth variation of coda waves attenuation using the SBS and SIS methods. In conclusion, the following results have been reached:

In this study, $Q_{c}=109 \pm 7 f^{0.87 \pm 0.04}$ and $Q_{c}=108 \pm 6 f^{0.86 \pm 0.03}$ were estimated using the vertical component seismograms of dataset- 1 at a coda window length of $25 \mathrm{~s}$, for the Alborz and NW Zagros regions, respectively. The average $Q_{\mathrm{c}}$ for the Alborz and NW Zagros regions were evaluated $\underline{Q}_{\mathrm{c}}=148 \pm 13 f^{0.81 \pm 0.05}$ and $\underline{Q}_{\mathrm{c}}=124 \pm 5 f^{0.89 \pm 0.03}$, respectively, by using dataset-2.These results derived for both dataset by applying the SBS method.

By applying the SIS model for the dataset-1, the obtained $Q_{c}$ in the Alborz and NW Zagros regions are $Q_{c}=111 \pm 8 f^{0.87 \pm 0.04}$ and $Q_{c}=111 \pm 6 f^{0.86 \pm 0.03}$ respectively. Also, by using the dataset 2 , the average $Q_{c}=149 \pm 13 f^{0.81 \pm 0.05}$ and $Q_{c}=126 \pm 5 f^{0.89 \pm 0.03}$ were estimated for the Alborz and NW Zagros regions, respectively.

The estimated $Q_{0}<200$ and $n>0.7$ through different coda window lengths in the study regions illustrate that the Earth's crust and upper mantle beneath the Alborz and NW Zagros are seismotectonically active and heterogeneous. Increasing $Q_{0}$ and decreasing $n$ parameter with coda window lengths or penetration-depths, shows that the heterogeneity level decreases with depth in both Alborz and NW Zagros regions. Rapid increasing of estimated $Q_{0}$ values for Alborz in comparison with those in Zagros, suggests that the lower lithosphere beneath NW Zagros is more attenuative.

As mentioned previously, the seismic wave attenuation was obtained from all three components. Estimated $Q_{c}$ values using different components show that there is no significant difference for using vertical and horizontal seismograms, so, it can be concluded that the degree of heterogeneity is same in the vertical and horizontal directions are essentially identical.

Acknowledgements. We thank the Iranian Seismological Network (ISRC) and the International Institute of Earthquake Engineering and Seismology (IIEES) for providing the required waveform data. We also thank Editor A. Bizzarri and two anonymous reviewers for their useful reviews, which improved the manuscript significantly.

\section{References}

Afonso, J. C., M. Fernande, G. Ronalli, W. L. Griffin and J.A.D. Connoly (2008). Integrated geophysical-petrological modeling of the lithospher and sub-lithosphere upper mantle: methodology and applications, Geochem. Geophyst, 9, no. 5, 1-36.; Q05008, doi:10.1029/2007GC00 1834.

Afsari, N., F. Sodoudi, F. Taghizadeh Ferahmand, and M.R. Ghassemi (2011). Crustal structure of Northwest Zagros (Kermanshah) and Central Iran (Yazd and Isfahan) using teleseismic Ps converted phases, Journal of Seismology, 15, 2, 341-353.

Aki, K. (1969). Analysis of the seismic coda of local earthquakes as scattered waves, J. Geophys. Res., 74, no. 2, 615-631. 


\section{Variation of coda wave attenuation in the Alborz and NW Zagros regions}

Aki, K. (1980). Attenuation of shear-waves in the lithosphere for frequencies from 0.05 to $25 \mathrm{~Hz}$., Phys. Earth planet In., 21, 50-60.

Aki, K., and B. Chouet (1975). Origin of coda waves: Source, attenuation and scattering effects, J. Geophys. Res., 80, 3322-3342.

Aki, K. (2003). Seismology of earthquake and volcanic prediction, in:Proceedings of the Seventh Workshop on Non Linear Dynamicsand Earthquake Prediction, The Abdus Salam International Centre for Theoretical Physics, Trieste, Italy, H4.SMR/1519-10.

Alavi, M. (1996). Tectonostratigraphic synthesis and structural style of the Alborz Mountain system in northern Iran, J. Geodyn., 21(1), 1-33.

Allen MB, MR. Ghassemi, M. Sharabi, and M. Qorashi (2003). Accommodation of late Cenozoic oblique shortening in the Alborz range, Iran, J. Struct. Geol., 25, 659-672.

Ambraseys, N.N., and C.P. Melville (1982). A history of Persian Earthquakes, Cambridge University Press, UK, 219.

Artemieva, I. M., M. Billien, JJ. Leveque, and W.D. Mooney (2004). Shear wave velocity, seismic attenuation, and thermal structure of the continental upper mantle. Geophys. J. Int., 157, 607-628.

Ashtari, M., D. Hatzfeld, and N. Kamalian (2005). Microseismicity in the region of Tehran, Tectonophysics, 395(34), 193-208.

Assereto, R. (1966). Explanatory Notes on the Geological Map of Upper Djadjerud and Lar Valleys (Central Elburz, Iran) (scale 1:50,000), Institute of Geology of the University of Milan.

Asudeh, I. (1982). Seismic structure of Iran from surface and body wave data, Geophys. J. R. Astron. Soc., 71, 715730.

Atkinson, G. M. (2004). Empirical attenuation of ground-motion spectral amplitudes in southeastern Canada and the northeastern United States. Bull. Seism. Soc. Am., 94, 1079-1095.

Baker, C., J. Jackson, and K. Priestley (1993). Earthquakes on the Kazerun line in the Zagros mountains of Iran: Strike-slip faulting within a fold-and-thrust belt, Geophys. J. Int., 115, 41-61.

Berberian M. (1995). Master blind thrust faults hidden under the Zagros folds: active basement tectonics and surface morphotectonics, Tectonophysics, 241, 193-224.

Berberian, M., and R. Walker (2010). The Rudbar Mw 7.3 earthquake of 1990 June 20; seismotectonics, coseismic and geomorphic displacements, and historic earthquakes of the western 'High-Alborz', Iran, Geophys. J. Int., 182(3), 1577-1602.

Birch, D. J., A. Cichowicz and D. Grobberlaar (2015). Q-coda estimation in the Kaapvaal Craton, The Journal of the Southern African Institute of Mining and Metallurgy (SAIMM), 115, 541-548.

Brockman, S. R. and G. A. Bollinger (1992). Q estimates along the Wasatch Front in Utah derived from Sg and Lg wave amplitudes, Bull. Seism. Soc. Am., 82, 135-147.

Calvet, M., and L. Margerin (2013). Lapse-time dependence of coda Q: anisotropic multiple-scattering models and application to the Pyrenees, Bull. Seism. Soc. Am., 103(3), 1993-2010.

Calvet, M., M. Sylvander, L. Margerin, and A. Villaseñor (2013). Spatial variations of seismic attenuation and heterogeneity in the Pyrenees: Coda Q and peak delay time analysis, Tectonophysics, 608, 428-439.

Canas, J. A., L. Pujades, M. J. Blanco, V. Soler and J. C. Carracedo (1995). Coda-Q distribution in the Canary Islands, Tectonophysics, 246, 245-261.

Casciello, E., J. Verges, E. Saura, G. Casini, N. Fernandez, E. Blanc, S. Homke and D. W. Hunt, (2009). Fold patterns and multilayer rheology of the Lurestan Province, Zagros Simply Folded Belt (Iran), J. Geol. Soc., 166, 947-959.

Chandler A. M., N. T. K. Lam and H. H. Tsang (2006). Near-surface attenuation modelling based on rock shear-wave velocity profile, Soil Dynamics and Earthquake Engineering, 26, 1004-1014.

Chun, K. Y., G. F. West, R. J. Kokoski, and C. Samson (1987). A novel technique for measuring Lg attenuation-Results from eastern Canada between 1 to $10 \mathrm{~Hz}$, Bull. Seism. Soc. Am., 77, 398-419.

Colman-Sadd, S. P. (1978). Fold development in Zagros simply folded belt, Southwest Iran, Am. Assoc. Petrol. Geol. Bull., 62, 984-1003.

Darzi, A., M. R. Zolfaghari, C. Cauzzi, and D. Fäh (2019). An Empirical Ground Motion Model for Horizontal PGV, PGA, and 5\% Damped Elastic Response Spectra (0.01-10 s) in Iran, Bull. Seism. Soc. Am., 109(3), 1041-1057.

De Lorenzo, S., E. Del Pezzo, and F. Bianco (2013). Qc, Q $\beta$, Qi and Qs attenuation parameters in the Umbria-Marche (Italy) region, Phys. Earth Planet. In., 218, 19-30.

De Siena, L., M. Calvet, K.J. Watson, A.R.T. Jonkers, and C. Thomas (2016). Seismic scattering and absorption mapping 


\section{Reza Emami et al.}

of debris flows, feeding paths, and tectonic units at Mount St. Helens volcano, Earth and Planetary Science Letters, 442, 21-31.

Dehghani, G., and J. Makris (1984). The gravity field and crustal structure of Iran, NeuesJahrb. Geol. Palaeontol. Abh., 168, 215-229.

Del Pezzo, E., F. Bianco, L. De Siena, and A. Zollo (2006). Small scale shallow attenuation structure at Mt. Vesuvius, Italy, Phys. Earth Planet. In., 157, 257-268.

Dobrynina, A. A., J. Albaric, A. Deschamps, J. Perrot, R. W. Ferdinand, J. Déverchère , V. A. San'kov and V. V. Chechel'nitskii (2017). Seismic wave attenuation in the lithosphere of the North Tanzanian divergence zone (East African rift system), Russian Geology and Geophysics, 58, 253-265.

Doloei, J., and R. Roberts (2003). Crust and uppermost mantle structure of Tehran region from analysis of teleseismic P waveform receiver functions, Tectonophysics, 364(3-4), 115-133.

Durek, J. J., M.H. Ritzwoller, and J. H. Woodhouse (1993). Constraining upper mantle anelasticity using surface wave amplitude anomalies, Geophys. J. Int., 114, 249-272.

Ekstrom, G. and P. England (1989). Seismic strain rates in regions of distributed continental deformation, J. geophys. Res., 94, 10231- 10257.

Emami, H., J. Verg'es, T. Nalpas, P. Gillespie, I. Sharp, R. Karpuz, E. J. P. Blanc, and M. G. H. Goodarzi (2010). Structure of the Mountain Front Flexure along the Anaran anticline in the Pusht-e Kuh Arc (NW Zagros, Iran): insights from sand box models, in Tectonic and Stratigraphic Evolution of Zagros and Makran during the MesozoicCenozoic, eds Leturmy, P. and Robin, C., Geol. Soc. Lond. Spec. Publ., 330, 78-155.

Engdahl, E. R., J. A. Jackson, S. C.Myers, E. A. Bergman, and K. Priestley (2006). Relocation and assessment of seismicity in the Iran region, Geophys. J. Int., 167, 761-778.

Falcon, N.L. (1961). Major earth-flexuring in the Zagros Mountains of south-west Iran, Q. J. geol. Soc. Land., 117(4), 367-376.

Falcon, N.L. (1967). The geology of the north-east margin of the Arabian basement shield, Advancement Sci., 24, 1-12.

Falcon, N.L. (1969). Problems of the relationship between surface structure and deep displacements illustrated by the Zagros Range, Geol. Soc. Lond. Spec. Publ., 3, 9-21.

Falcon, N. (1974). Southern Iran: Zagros Mountains. In: Spencer, A., Ed., Mesozoic-Cenozoic Orogenic Belts, Geol. Soc. Lond. Spec. Publ., 4, 199-211. http://dx.doi.org/10.1144 /GSL.SP.2005.004.01.11

Farrokhi, M., H. Hamzehloo, H. Rahimi, and M. Allamehzadeh (2015). Estimation of coda-wave attenuation in the central and eastern Alborz, Iran, Bull. Seism. Soc. Am., 105, 1756-1757.

Farrokhi, M., H. Hamzehloo, H. Rahimi and M. Allameh Zadeh (2016). Separation of intrinsic and scattering attenuation in the crust of central and eastern Alborz region, Iran, Physics of the Earth and Planetary Interior, 253, 88-96.

Furumura, T., and B. L. N. Kennett (2008). A scattering waveguide in the heterogeneous subducting plate, in: Dmowska, R. (Ed.), Earth Heterogeneityand Scattering Effects on Seismic Waves, Adv. Geophys., 50, $195-217$.

Galluzzo, D., La Rocca, M., Margerin, L., Del Pezzo, E., and Scarpa, R. (2015). Attenuation and velocity structure from diffuse coda waves: Constraints from underground array data. Physics of the Earth and Planetary Interiors, 240, 34-42.

Gao, L. S., L. C., Lee, N. N. Biswas, and K., Aki (1983). Comparison of the effects between single and multiple scattering on coda waves for local earthquakes, Bull. seism. Soc. Am., 73, 377-389.

Gao, L.S. (1992). Physical meaning of the coda envelopes. In: Volcanic Seismology, P. Gasparini, R. Scarpa, K. Aki (Editors) Springer-Verlag, Berlin, Germany, 391-403.

Ghasemi, H., M. Zare, Y. Fukushima, and K. Koketsu (2009). An empirical spectral ground motion model for Iran, J. Seismol., 13, 499-515.

Gupta, S. C., S. S. Teotia and N. Gautam (1998). Coda Q estimates in the Koyna region, India, Pure appl. Geophys., 153, 713-731.

Havskov J., S. Malone, D. McClury and R. Crosson (1989). Coda-Q for the State of Washington, Bull. Seism. Soc. Am., 79, 1024- 1038 .

Havskov, J., B. S. Mathilde, D. Vales, M. Özyazıcıoğlu, G. Sánchez and B. Li (2016). Coda Q in Different Tectonic Areas, Influence of Processing Parameters, Bull. Seism. Soc. Am., 106, no. 3, 956-970.

Hessami, Kh. and F. Jamali (2006). Explanatory notes to the map of Major Active Faults of Iran, Journal of Seismology and Earthquake Engineering, 8 (1), 1-11. 


\section{Variation of coda wave attenuation in the Alborz and NW Zagros regions}

Irandust, M. A., F. Sobouti, and H. Rahimi (2015). Lateral and depth variation of coda Q in the Zagros region of Iran, Journal of Seismology, 20(1), 197-211.

Jackson J., K. Priestley, M. Allen, and M. Berberian (2000). Active tectonics of the south Caspian basin, Geophys. J. Int., 148, 214-245.

Jackson, D. D. and D. L. Anderson (1974). Physical mechanism of seismic-waves attenuation, Rev. Geophys. Space Phys., 8, 1-63.

Jackson, J. A., and D. P. McKenzei (1984). Active tectonics of the Alpine-Himalayan belt between Turkey and Pakistan, Geophy. Journ. Roy Astron Soc. London, 77, 185-264.

Jackson, J. A., and D. P. McKenzei (1988). The relationship between plate motions and seismic moment tensors, and the rates of active deformation in the Mediterranean and Middle-East, Geophys. Journ., 93, 45-73.

Jackson, J. A. (1987). Active continental deformation and regional metamorphism, Phil. Trans. R. Soc. Lond. A., 321, $47-63$.

Jackson, J. A., K. Priestley, M. Allen, and M. Berberian, (2002). Active tectonics of the South Caspian Basin, Geophys. J. Int., 148, 214-245.

James, G. A. and J. G. Wynd (1965). Stratigraphic Nomenclature of Iranian Oil Consortium Agreement Area, Am. Assoc. Petrol. Geol. Bull., 49, 2182-2245.

Jimenez-Munt, I., M. Fernandez, E. Saura, J. Verg'es and D. Garc'1a-Castellanos (2012). 3D lithospheric structure and regional/residual Bouguer anomalies from Arabia-Eurasia collision (Iran), Geophys. J. Int., 190, 13111324.

Jin A., and K. Aki (2005). High-resolution maps of coda Q in Japan and their interpretation by the brittle-ductile interaction hypothesis. Earth Planets Space, 57, 403-409.

Kim, S. K., J. Y. Yang, and J. Oh (2006). Q-values for P and S waves in the southern Korean Peninsula based on the coda-normalization method, Geosciences Journal, 10, no. 4, 465-477.

Khadivi, S. (2010). Tectonic evolution and growth of the Zagros Mountain Belt (Fars, Iran): constraints from magnetostratigraphy, sedimentology and low- temperature thermochronometry. Earth Sciences. Université Pierre et Marie Curie - Paris VI. English. fftel-00642547f.

Kopnichev, Yu. F. (1991). New data on the structure of the upper mantle of the Baikal rift system, Dokl. Akad. Nauk SSSR, 325 (5), 944-949.

Kumar, N., I. A. Parvez, and H. Virk (2005). Estimation of coda wave attenuation for NW Himalayan region using local earthquakes, Phys. Earth Planet.In., 151, no. 3, 243-258.

Longston, C. A. (2003). Local earthquake wave propagation through Mississipi embayment sediments, part I: Bodywave phases and local site responses, Bull. Seism. Soc. Am., 93, 2664-2684.

Ma'hood, M. (2014). Attenuation of High-Frequency Seismic Waves in Eastern Iran. Pure Appl. Geophys., 171, 22252240.

Ma'hood, M., and H. Hamzehloo (2009). Estimation of coda wave attenuation in east central Iran, J. Seismol., 13, no. $1,125-139$.

Mak, S., L. S. Chan, A. M. Chandler, and R. Koo (2004). Coda Q estimates in the Hong Kong region, J. Asian Earth Sci., $24,127-136$.

Malin, P. E. (1978). A first order scattering solution for modelling lunar and terrestrial seismic codas, Ph.D. Dissertation, Princeton University.

Masson, F., Y. Djamour, S. Van Gorp, J. Chéry, M. Tatar, F. Tavakoli, H. Nankali, and P. Vernant (2006). Extension in NW Iran driven by the motion of the South Caspian Basin, Earth Planet. Sci. Lett., 252(1-2), 180-188.

McKenzie, D. (1981). The variation of temperature with time and hydrocarbon maturation in sedimentary basins formed by extension, Earth planet. Sci. Lett., 55, 87-98.

Mirzaei, N., E. Shabani, and S.H. Mousavi-bafrouei (2014). "Comment on "A Unified Seismic Catalog for the Iranian Plateau (1900-2011)” by Mohammad P. Shahvar, Mehdi Zare, and Silvia Castellaro.”, Seismol. Res. Lett., 85, no. $1,179-183$.

Mirzaei, N., G. Mengtan and C. Yuntai (1998). Seismic Source Regionalization for Seismic Zoning of Iran: Major Seismotectonic Provinces, Journal of Earthquakes Prediction Research, 7, 465-495.

Mitchell, B. J. (1995). Anelastic structure and evolution of the continental crust and upper mantle from seismic surface wave attenuation, Rev. Geophys., 33, 441-462.

Mohammadi, E., F. Sodoudi, R. Kind, and M. Rezapour (2013). Presence of a layered lithosphere beneath the Zagros 


\section{Reza Emami et al.}

collision zone. Tectonophysics, 608, 366-375.

Mokhtari, M., A. M. Farahbod, C. Lindholm, M. Alahyarkhani, and H. Bungum (2004). An approach to a comprehensive Moho depth map and crust and upper mantle velocity model for Iran, Iranian Int. J. Sci., 5(2), 223-244.

Molinaro, M., P. Leturmy, J. C. Guezou, D. Frizon de Lamotte, and S. A. Eshraghi (2005). The structure and kinematics of the southeastern Zagros fold thrust belt, Iran: from thin-skinned to thick-skinned tectonics, Tectonics, 24(3), 1-19; TC3007, doi:10.1029/ 2004TC001633.

Molnar, M. (2006). Tertiary Development of the Zagros Mountains, Geol 418-Earth History.

Motaghi, K., and A. Ghods (2012). Attenuation of ground-motion spectral amplitudes and its variations across the central Alborz Mountains, Bull. Seism. Soc. Am., 102, 1417-1428.

Motaghi, K., M. Tatar, K. Priestley, F. Romanelli, C. Doglioni and G. F. Panza (2014). The deep structure of the Iranian Plateau, Gondwana Research, 28 (1), 407-418, http:// dx.doi.org/10.1016/ j.gr.2014.04.009.

Motazedian, D. (2006). Region-specific key seismic parameters for earthquakes in northern Iran, Bull. Seism. Soc. Am., 96, 1383-1395.

Mukhopadhyay, S., C. Tyagi, and S. S. Rai (2006). The attenuation mechanism of seismic waves in northwestern Himalayas, Geophy. J. Int., 167, 354-360.

Naghavi, M., H. Rahimi, A. Moradi, and S. Mukhopadhayay (2017). Spatial variation of seismic attenuation in the North West of Iranian plateau from analysis of coda waves, Tectonophysics, 708, 70-80.

Ni, J., and M. Barazangi (1986). Seismotectonics of the Zagros continental collision zone and a comparison with the Himalayas, J. Geophys. Res., 91, 8205-8218.

Niazi, N., I. Asudeh, J. Ballard, J. Jackson, K. King, and D. McKenzie (1978). The depth of seismicity in the Kermanshah region of the Zagros Mountains, Iran, Earth Planet Sci. Lett., 40, 270-274.

Nissen, E., M. Tatar, J. A. Jackson, and M. B. Allen (2011). New views on earthquake faulting in the Zagros fold-andthrust belt of Iran, Geophys. J. Int., 186, 928-944.

Novelo-Casanova D. A., and W. H. K. Lee (1991). Comparison of techniques that use the single scattering model to compute the quality factor $\mathrm{Q}$ from coda waves, PAGEOPH, 135, no. 1, 77-89.

Nowroozi, A. A. (1972). Focal mechanism of earthquakes in Persia, Turkey, West Pakistan and Afghanistan and plate tectonics of the Middle East. Bull. Seism. Soc. Am., 62 (3), 832-850.

O’Brien, C. A. E. (1957). Salt diapirism in south Persia, Geologie en Mijnbouw, 19, 357-376.

Obermann, A., T. Planes, E. Larose, C. Sens-Schonfelder and M. Campillo (2012). Depth sensitivity of seismic coda waves to velocity perturbations in an elastic heterogeneous medium, Geophys. J. Int., 194(1), 372-382.

Parvez, I.A., A. K. Sutar, M. Mridula, S. K. Mishra and S. S. Rai (2008). Coda Q Estimation in the Andaman Islands Using Local Earthquakes, Pure appl. Geophys., 165, 1861-1878.

Paul, A., A. Kaviani, D. Hatzfeld, J. Vegne, and M. Mokhtari (2006). Seismological evidence for crustal-scale thrusting in the Zagros mountain belt (Iran). Geophys. J. Int., 166, 227-237.

Paul, A., D. Hatzfeld, A. Kaviani, M. Tatar, and C. Pequegnat, (2010). Seismic imaging of the lithospheric structure of the Zagros mountain belt (Iran), Geol. Soc. London Spec. Publ., 330(1), 5-18.

Petukhin, A., K. Irikura, S. Ohmi, and T. Kagawa (2003). Estimation of Q-values in the seismogenic and aseismic layers in the Kinki Region, Japan, by elimination of the geometrical spreading effect using ray approximation, Bull. Seism. Soc. Am., 93, 1498-1515.

Pujades, L., J. A. Canas, J. J. Egozcue, M. A. Puigvi, J. Pous, J. Gallart, X. Lana, and A. Casas (1991). Coda Q distribution in the Iberian Peninsula, Geophys. J. Int., 100, 285-301.

Pulli, J.J. (1984). Attenuation of coda waves in New England, Bull. Seism. Soc. Am., 74, 1149-1166.

Radjaee, A. H., M. Mokhtari, K. Priestley, and D. Hatzfeld (2007). Variation of Moho depth in the central Alborz [in Persian], Geosci. Sci. Q. J., 16(64), 136-147.

Rahimi, H., K. Motaghi, S. Mukhopadhyay, and H. Hamzehloo (2010). Variation of coda wave attenuation in the Alborz region and central Iran. Geophys. J. Int., 181(3), 1643-1654.

Rahimi, H., and H. Hamzehloo (2008). Lapse time and frequency-dependent attenuation of coda waves in the Zagros continental collision zone in southwestern Iran, J. Geophys. Eng., 5, no. 2, 173.

Rastgoo, M., H. Rahimi, Kh. Motaghi, E. Shabanian, and F. Romanelli (2018). Deep structure of the Alborz Mountains by joint inversion of $\mathrm{P}$ receiver functions and dispersion curves, Physics of the Earth and Planetary Interiors, 277, 70-80. 


\section{Variation of coda wave attenuation in the Alborz and NW Zagros regions}

Rautian, T. G., and V. I. Khalturin (1978). The use of coda for determination of the earthquake source spectrum, Bull. Seism. Soc. Am., 68, 923-948.

Ritz, J.-F., H. B. Nazari, A. Ghassemi, R. Salamati, A. Shafei, S. Solaymani, and P. Vernant (2006). Active transtension inside central Alborz: A new insight into northern Iran-southern Caspian geodynamics, Geology, 34(6), 477490.

Roecker, S., B. Tucker, J. King, and D. Hatzfeld (1982). Estimates of Q in central Asia as a function of frequency and depth using the coda of locally recorded earthquakes, Bull. Seism. Soc. Am., 72, no. 1, 129-149.

Rogers, A. M., S. C. Harmsen, R. B. Hermann, and M. E. Meremonte (1987). A study of ground motion in the Southern Great Basin, Nevada-California, using several techniques for estimation of Qs, $\log$ Ao, and Coda Q, J. Geophys. Res., 92, 3527-3540.

Romanowicz, B. (1994). Anelastic tomography: a new perspective on uppermantle thermal structure, Earth planet. Sci. Lett., 128, 113-121.

Romanowicz, B. (1995). A global tomographic model of shear attenuation in the upper mantle, J. Geophys. Res., 100, 12 375-12 394.

Sato, H. (1977). Energy propagation including scattering effects: Single isotropic approximation, J. Phys. Earth, 25, 27-41.

Sato, H., M. C. Fehler (1998). Seismic Wave Propagation and Scattering in the Heterogeneous Earth, Springer-Verlag, New York.

Sato, H., M. C. Fehler, and T. Maeda (2012). Seismic Wave Propagation and Scattering in the Heterogeneous Earth, Second Ed., Springer, New York, New York, 1-496.

Savage, W. U., J. N. Alt, and A. Mohajer-Ashjai (1977). Microearthquake investigations of the 1972 Qir, Iran, earthquake zone and adjacent areas, Abstr. Programs Geol. Soc. Am., 9, 496.

Scherbaum, F., and C. Kisslinger (1985). Coda Q in the Adak seismic zone, Bull. Seism. Soc. Am., 75, 615-620.

Sedaghati, F., and S. Pezeshk (2016a). Estimation of the Coda-Wave Attenuation and Geometrical Spreading in the New Madrid Seismic Zone, Bull. Seism. Soc. Am., 106, no. 4, 1482-1498.

Sedaghati, F., and S. Pezeshk (2016b). Investigation of regional differences in strong ground motions for the Iranian plateau, World Acad. Sci. Eng. Tech., Int. J. Environ. Chem. Ecol. Geol. Geophys. Eng., 10, no. 6, 591-594

Sepehr, M. and J. W. Cosgrove (2004). Structural framework of the Zagros fold-thrust belt, Iran, Mar. Petrol. Geol., 21(7), 829-843.

Sertçelik, F. (2011). Estimation of coda wave attenuation in the east Anatolia fault zone, Turkey, Pure Appl. Geophys., $169,1189-1204$.

Shapiro MN., M. Campillo, L. Margerin, SK. Singh, V. Kostoglodov, and J. Pacheco (2000). Energy partitioning and the diffuse character of the seismic coda. Bull. Seism. Soc. Am., 90, 655-665.

Sharma, B., P. Chingtham, A. K. Sutar, S. Chopra, and H. P. Shukla (2015). Frequency dependent attenuation of seismic waves for Delhi and surrounding area, India, Annals of Geophysics, 58, 2, S0216; doi:10.4401/ag-6636.

Shin, T. C. and R. B. Hermann (1987). Lg attenuation and source studies using 1982 Miramichi data, Bull. Seism. Soc. Am., 77, 384-397.

Shoja-Taheri J., and M. Niazi (1981). Seismicity of the Iranian plateau and bordering regions, Bull. Seism. Soc. Am., $71,477-489$.

Singh, S., and R. B. Herrmann (1983). Regionalization of crustal coda Q in the continental United States, J. Geophys. Res., 88, no. B1, 527-538.

Singh, S.K., D. Garcia, J.F. Pacheco, R. Valenzuela, B.K. Bansal, and R.S. Dattatrayam, (2004). Q of the Indian Shield, Bull. Seism. Soc. Am., 94, 1564-1570.

Soham, B. and K. Abhishek (2016). Determination of seismic wave attenuation: A Review, Disaster Advanced, 6, 10-27.

Stocklin J. (1968). Structural history and tectonics of Iran, Bull. Am. As. Petrol. Geol., 52, 1229-1258.

Synder, D. B., and M. Barazangi (1986). Deep crustal structure and flexure of the Arabian plate beneath the Zagros collisional mountain belt as inferred from gravity observations, Tectonics, 5, 361-73.

Talebian M. and J. Jackson (2004). A reappraisal of earthquake focal mechanisms and active shortening in the Zagros mountains of Iran, Geophys. J. Int., 156, 506-526.

Tatar, M. (2001). Étudesismotectonique de deux zones de collision continentale: Le Zagros Central etl’Alborz (Iran), Ph.D. thesis, Univ. de Grenoble, Grenoble, France.

Tatar, M., J. Jackson, D. Hatzfeld, and E. Bergman (2007). The 2004 May 28 Baladeh earthquake (Mw 6.2) in the 


\section{Reza Emami et al.}

Alborz, Iran: overthrusting the south Caspian basin margin, partitioning of oblique convergence and the seismic hazard of Tehran”, Geophys. J. Int., 170, 249-261; doi:10.1111/j.1365-246X.2007.03386.x

Teknik, V., and A. Ghods (2017). Depth of magnetic basement in Iran based on fractal spectral analysis of aeromagnetic data, Geophys. J. Int., 209, 1878-1891.

Tunini, L., I. Jimenez-Munt, M. Fernandez, J. Veges, and A. Villasenor (2015). Lithospheric mantle heterogeneities beneath the Zagros Mountains and Iranian Plateau: a petrological-geophysical study, Geophys. J. Int., 200, 596-614.

Tuve T, F. Bianco, J. Ibáñez, D. Patanè, ED. Pezzo, and A. Bottari (2006). Attenuation study in the Straits of Messina area (southern Italy), Tectonophysics, 421, 173-185.

Ugalde, A., C. A. Vargas, L. G. Pujades, and J. A. Canas (2002). Seismic coda attenuation after the Mw $=6.2$ Armenia (Colombia) earthquake of 25 January 1999, J. Geophys. Res., 107, no. B6, 1-13.

Verges, J., E. Saura, E. Casciello, M. Fern `andez, A. Villase`nor, I. Jim’enez- Munt, and D. Garc'ia-Castellanos (2011). Crustal-scale cross section across the NW Zagros Belt: implications for the Arabian Margin reconstruction, Geol. Mag., 148, 739-761.

Vernant, P., F. Nilforoushan, D. Hatzfeld, M. R. Abbasi, C. Vigny, F.Masson, H. Nankali, J. Martinod, A. Ashtiani, R. Bayer, F. Tavakoli and J. Chery (2004). Present-day crustal deformation and plate kinematics in the Middle East constrained by GPS measurements in Iran and northern Oman, Geophys. J. Int., 157, 381-398.

Von Dollen, F. J., J. N. Alt, D. Tocher, and A. Nowroozi (1977). Seismological and geological investigations near Bandar Abbas, Iran, Abstr. Programs Geol. Soc. Am., 9, 521.

Woodgold, C. R. D. (1994). Coda Q in the Charlevoix, Quebec, Region: Lapse-time dependence and spatial and temporal comparisons, Bull. Seism. Soc. Am., 84, 1123-1131.

Woong Chung, T., J. M. Lees, K. Yoshimoto, E. Fujita and M. Ukawa (2009). Intrinsic and scattering attenuation of the Mt Fuji Region, Japan, Geophys. J. Int., 177, 1366-1382.

Zamani, A. and M. Agh-Atabai (2011). Multifractal analysis of the spatial distribution of earthquake epicenters in the Zagros and Alborz-KopehDagh regions of Iran, Iranian Journal of Science and Technology, A1, 39-51.

Zelt, B. C., N. T. Dotzev, R. M. Ellisand and G. C. Rogers (1999). Coda Q in southwestern British Columbia, Canada, Bull. Seism. Soc. Am., 89, 1083- 1093. 